Estudios sobre armas antiguas, arte militar y vida cultural en oriente y occidente XXXIII (2013), pp. 81-112 ISSN : 0436-029X

doi: $10.3989 /$ gladius.2013.0004

\title{
BROCHES DE CINTURÓN DE TIPO HISPANO EN CÁSTULO: UNA CONTRIBUCIÓN AL EJÉRCITO BAJO IMPERIAL EN HISPANIA
}

\author{
AGRAFES DE CEINTURE DE TYPE HISPANIQUE À CASTULO: UNE CONTRIBUTION À \\ L'ÉTUDE DE L'ARMÉE ROMAINE TARDIVE DANS L'HISPANIA
}

POR

\section{Bautista Ceprián del Castillo*, Carmen Repullo Roldán*** y Jorge Alarcón Fernández ${ }^{* * *}$}

\section{RESUMEN - RÉSUMÉ}

Con motivo en 2009 de una excavación arqueológica en la ciudad ibero-romana de Cástulo (Linares, Jaén) se halló un broche de cinturón de tipo Simancas I (grupo Hispano de Aurrecoechea (2001: pp. 155 y ss.) en un contexto cronológico de primera mitad del s. V. Ante la ubicación de este tipo de elementos en un contexto urbano planteamos la hipótesis de que los broches de tipo hispano, de cronología bajo imperial, sean parte de la indumentaria del ejército regular romano. Por un lado, un análisis de la producción formal de dichos broches y su comparación con los de tipo no-hispanos y pseudo/hispanos de carácter militar (Aurrecoechea, 2001: pp. 107 y ss.) y, por otro, un estudio estadístico sobre la distribución de ambos tipos, permiten demostrar el carácter castrense de los broches hispanos. También se concreta la presencia militar en Cástulo y su inserción en la política geoestratégica imperial asignada al ejército de Hispania en el bajo imperio (Fernández y Morillo, 1997: p. 739).

Avec motif en 2009 d'une excavation archéologique dans la ville ibère - romaine de Cástulo (Linares, Jaén) un boucle de ceinture type de Simancas I (groupe hispanique d'Aurrecoechea (2001: pp. 155 y ss.), s'est trouvé dans un contexte chronologique de première moitié de s. V. Devant la situation de ce type d'éléments dans un contexte urbain, nous proposons l'hypothèse de que les boucles de type hispanique, de chronologie sous impérial, font partie du costume de l'armée régulière romaine. D’une part, une analyse de la production formelle ces fermoirs et de leur comparaison avec ceux de type non-hispaniques et pseudo/hispaniques de caractère militaire (Aurrecoechea, 2001:pp.107 y ss.) et, par un autre, une étude statistique sur la distribution des deux types, permettent de démontrer le caractère militaire des boucles hispaniques. La boucle permet délimiter aussi la présence militaire en Cástulo et son insertion dans la politique géo-stratégique impériale assignée à l'armée de Hispania dans le bas empire (Fernández y Morillo, 1997: p. 739).

\section{Palabras Clave - Mots Clé}

Broches de cinturón; Cingulum; Ejército; Bajo imperio; Cástulo; Vías; Roma.

Boucles de ceinture; Cingulum; Armée; Bas empire; Cástulo; Voies; Rome.

* Proyecto Cástulo MMX. Universidad de Jaén. Museo Arqueológico de Linares Monográfico de Cástulo, bautista. ceprian.ext@juntadeandalucia.es.

** Museo de Jaén, mariac.repullo@juntadeandalucia.es.

*** Fundación Formación y Empleo Miguel Escalera (FOREM), joalfernandez@hotmail.com. 


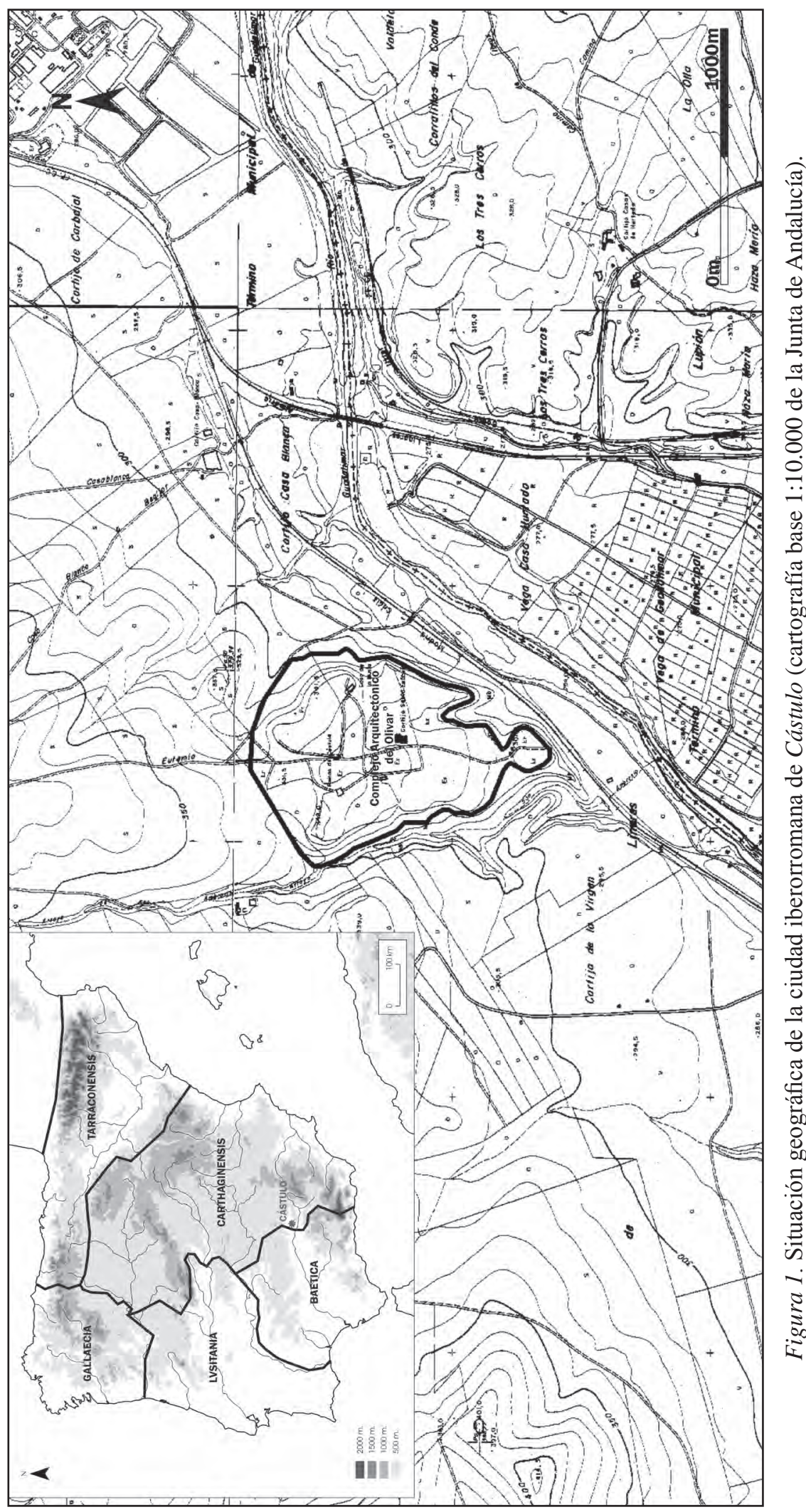

Gladius, XXX XIII (2013), pp. 81-112. ISSN : 0436-029X . doi: 10.3989/gladius.2013.0004 


\section{HALLAZGOS Y CONTEXTO ARQUEOLÓGICO}

El resultado de este trabajo se enmarca en una actividad arqueológica ${ }^{1}$ de apoyo a la restauración del hypocaustum de las termas del «Conjunto Arquitectónico del Olivar de Cástulo» que por diferentes causas había sido parcialmente destruido. Con el fin de realizar de manera objetiva y precisa la correcta anastilosis se excavó en extensión el caldarium septentrional y el pasillo/propigneum central de dicha estructura. En esta excavación se corroboró el uso del edificio como terma pública en el s. IV (Blázquez y García-Gelavert, 1999: p. 156). Posteriormente, a finales del s. IV o principios del s. V., el edificio pierde su función termal por otro uso aún impreciso al que le seguiría un abandono pacífico y una destrucción lenta de la construcción. En esta última fase de cambio de uso del edificio fue hallado un fragmento de broche de cinturón de tipo hispano (Aurrecoechea, 2001: pp. 155 y ss.). El análisis de producción formal y su comparación con los broches contemporáneos de tipo no-hispanos y pseudo/hispanos (Aurrecoechea, 2001: pp. 107 y ss.) de indudable carácter militar y un estudio estadístico sobre la distribución de ambos tipos, indican el carácter castrense de los broches del grupo hispánico. Estos resultados permiten concretar la presencia militar en Cástulo y su inserción en la política geoestratégica imperial asignada al ejército de Hispania en el bajo imperio.

El conjunto arqueológico de la antigua ciudad ibero-romana de Cástulo se sitúa en la región del Alto Guadalquivir en la provincia de Jaén, dentro del término municipal de Linares, concretamente sobre una meseta de algo más de unos 300 m.s.n.m. en la orilla izquierda del río Guadalimar, afluente del Guadalquivir (fig. 1).

Cástulo, en el periodo romano se convirtió en una importante y próspera ciudad gracias a la explotación de las minas de plata y plomo de su territorio. Desde el punto de vista administrativo, Augusto incluyó la ciudad en la provincia imperial de la Tarraconense, para poder gestionar, controlar y beneficiarse de los metales extraídos en su territorio (Castillo, 2004, p. 14; Arboledas, 2010: p. 180). Posteriormente, cuando Diocleciano desgajó la provincia Cartaginense de la Tarraconense, la ciudad pasó a depender de la primera por su ubicación geográfica.

Pues bien, como hemos expresado más arriba, en las excavaciones realizadas en 2009 en este yacimiento arqueológico, en las termas del denominado «Complejo arquitectónico del Olivar» (Blázquez y García-Gelavert, 1999: p. 35) fue hallado un broche de cinturón de tipo Simancas I (fig. 2) con la placa decorada con el típico motivo de arquerías u ojos de cerradura en opus interrasile (fig. 3).

Del análisis estratigráfico se puede deducir que el nivel en que se depositó la pieza (US 4) es posterior al estrato de uso termal del edificio (US 10) (tabla 1). Por otro lado, el final del uso de la construcción como edificio termal está bien referenciado en relación a la ocultación a techo de la US 10 de un tesorillo en un largo pasillo/propigneum que daba servicio a varios praefurnia del hypocaustum. Tras un estudio parcial de las monedas del tesorillo, las emisiones más modernas que se han identificado son de los emperadores Magno Máximo y Teodosio lo que nos da una fecha de ocultación aproximada de finales del s. IV a principios del s. V. Se deduce que ésta es la fecha en la que las termas pierden su uso primitivo, puesto que el ocultador del tesorillo sólo pudo elegir el pasillo subterráneo si esta zona estaba ya abandonada. De esta manera, como el estrato US 4 se formó inmediatamente después del estrato US 10, podemos concretar una cronología general post quem de primera mitad del s. V tanto para el

1 La actividad arqueológica se denominó “Actividad Arqueológica Puntual de Apoyo a la Restauración en el Hypocaustum de las Termas de Cástulo (Linares, Jaén)”. Fue financiada por la Consejería de Cultura de la Junta de Andalucía y dirigida por uno de los autores firmantes de este trabajo, Bautista Ceprián”. 


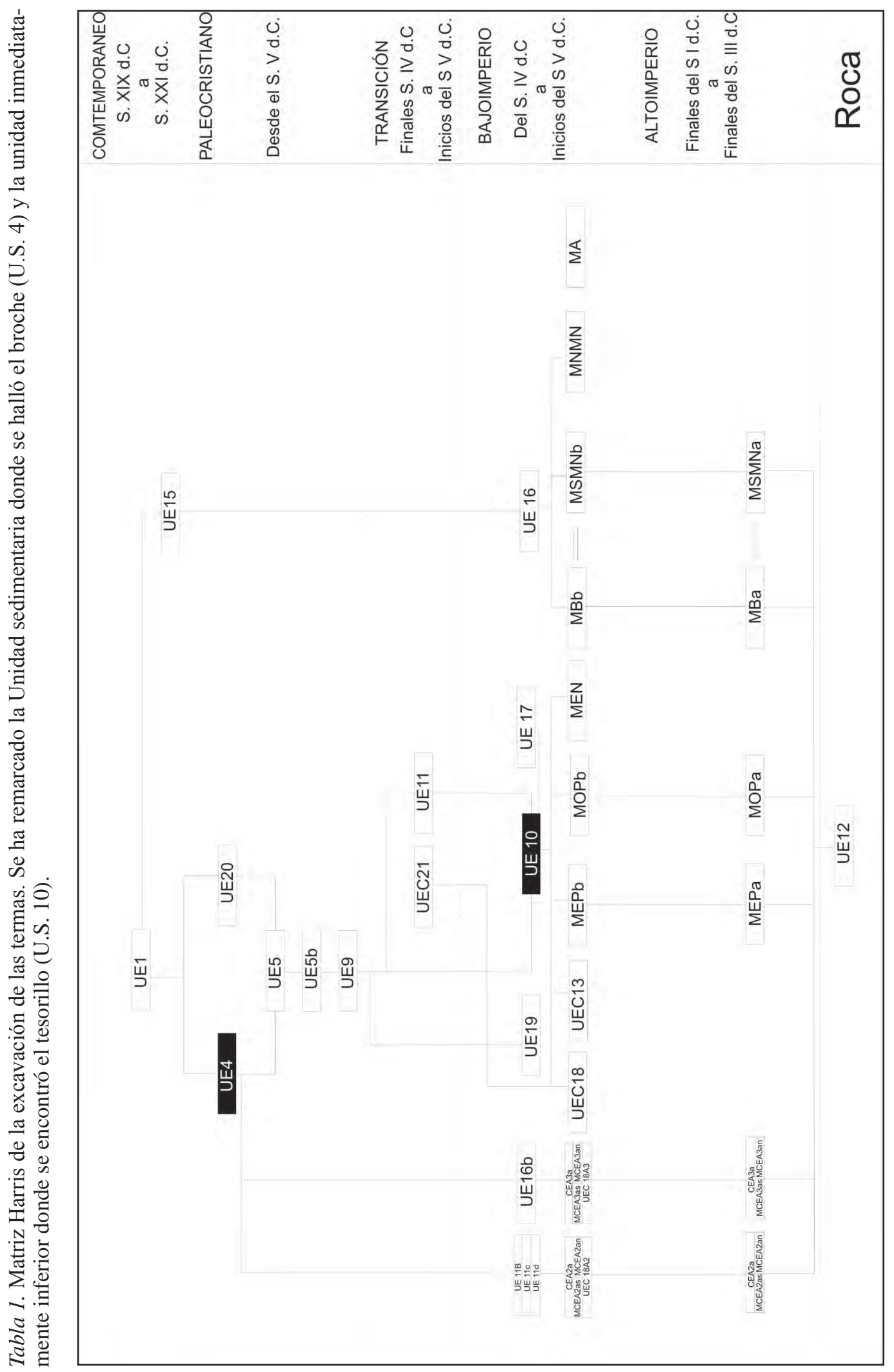

Gladius, XXX XIII (2013), pp. 81-112. ISSN: 0436-029X . doi: 10.3989/gladius.2013.0004 
estrato como para los materiales arqueológicos contenidos en él. En este sentido, las sigillatas halladas en dicho nivel compuestas por fragmentos de hispánicas tardías, hispánicas tardía meridionales y africanas vienen a redundar en esta fecha de formación. En definitiva, podemos dar al broche una cronología contextual del s. V, fecha que coincide con las asignadas al uso de estos elementos, entre la segunda mitad del s. IV y la primera mitad del s. V (Aurrecoechea, 2001: pp. 88 a 97).

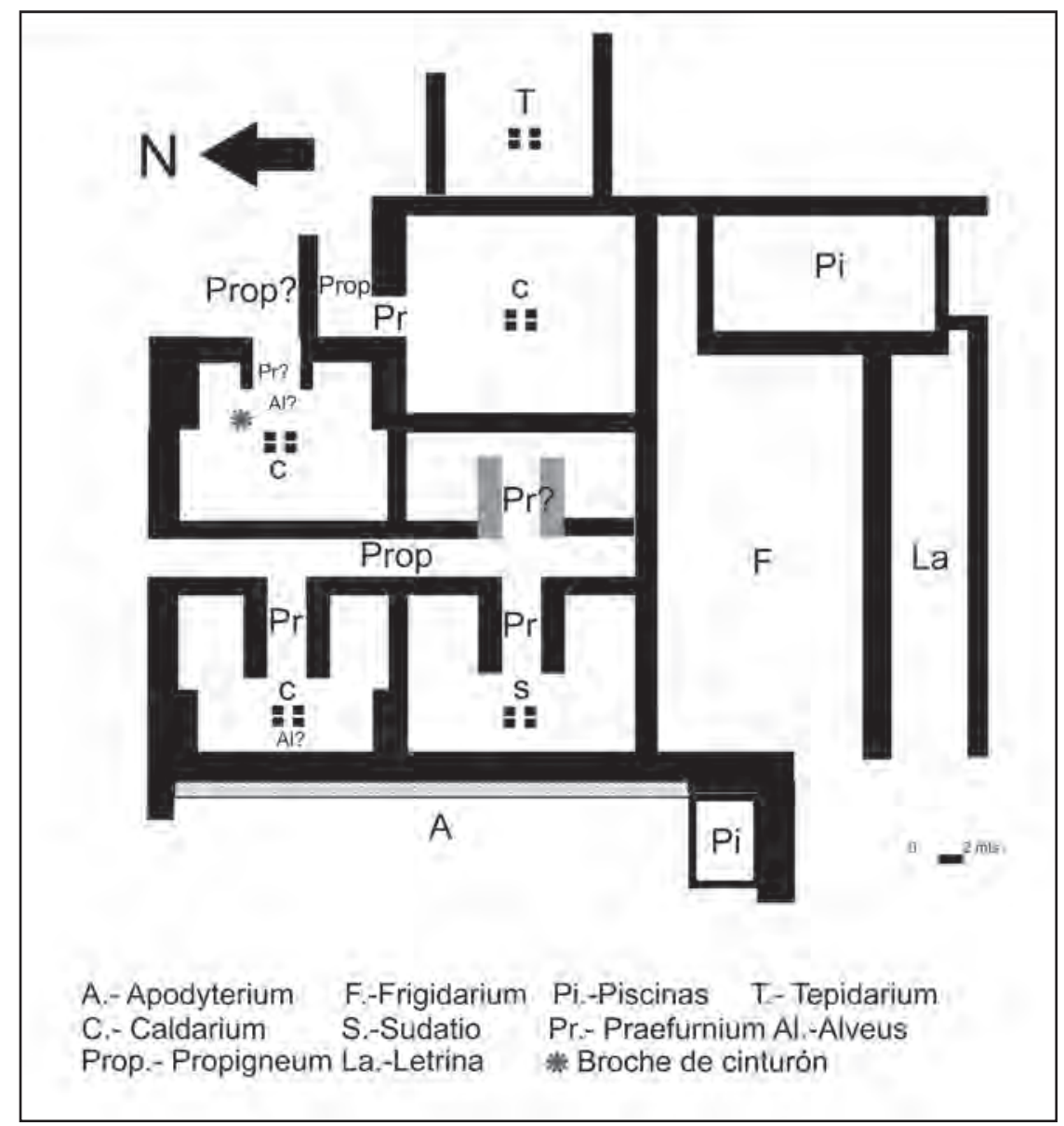

Figura 2. Ubicación del broche de tipo Simancas en las termas públicas del Complejo Arquitectónico del Olivar (Cástulo).

Nos encontramos, por tanto, ante un broche de cinturón de tipo Simancas I, perteneciente al grupo denominado hispano (Aurrecoechea, 2001: p. 147), en un contexto urbano. No obstante, no es la única pieza de esta tipología hallada en Cástulo, ya que al broche actual ha de añadirse una hebilla cornuda (Aurrecoechea, 2001: p. 158, il. 64/7) (fig. 3), recogida de antiguo en el yacimiento sin metodología arqueológica, que debe asignarse a esa tipología de broches puesto que estas hebillas bajoimperiales «por el momento se vinculan siempre a broches de la clases «Simancas» (Aurrecoechea, 2001: p. 155).

Estos broches eran los elementos de cierre del cinturón o cingulum, cuyo uso era específico en la indumentaria como prenda destinada a portar algún tipo de arma (Aurrecoechea, 2001: 


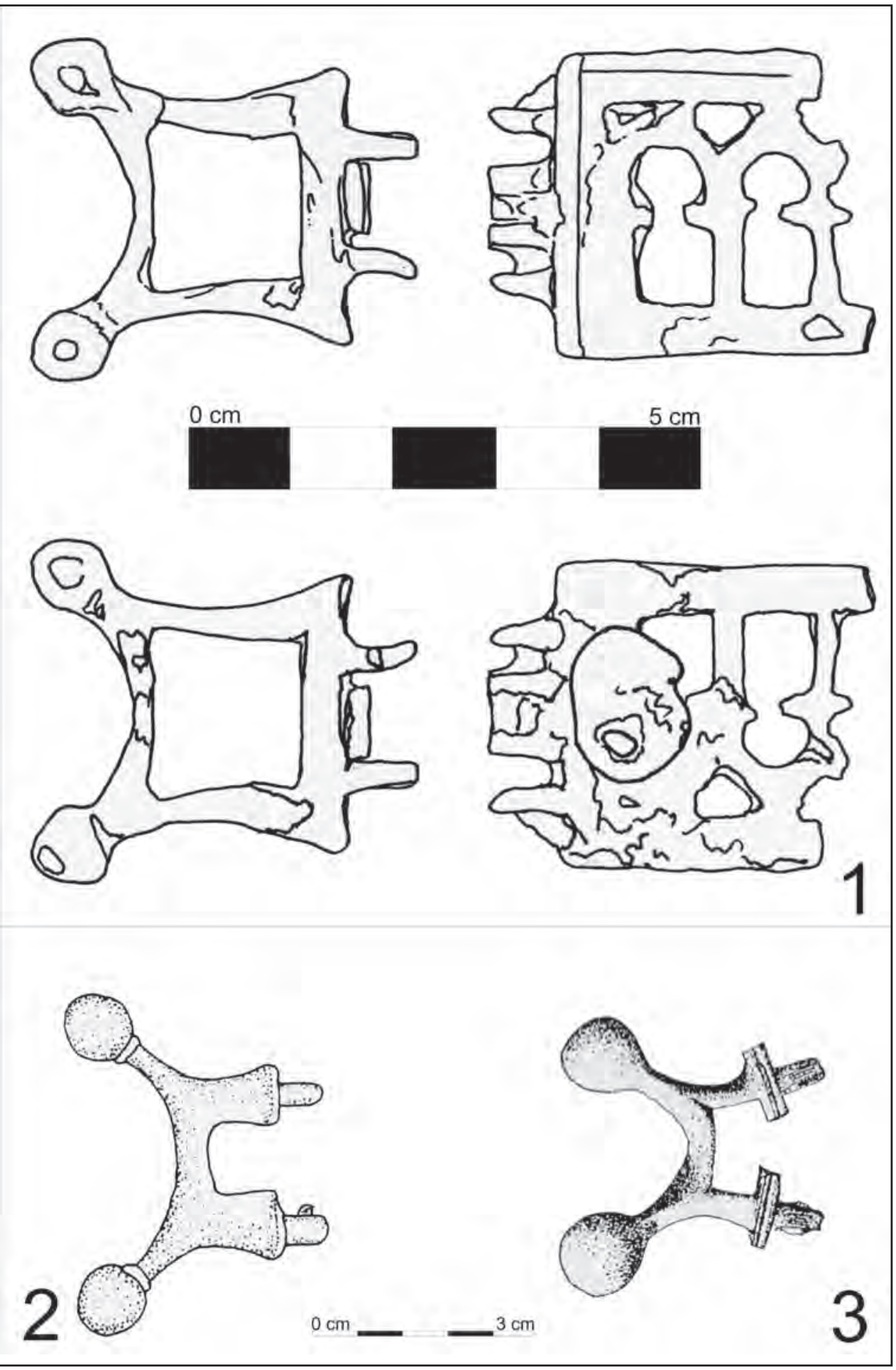

Figura 3. (1) Broche de tipo Simancas I de las termas de Cástulo (Museo arqueológico de Cástulo. Dibujo: Carmen Repullo). (2) Hebilla cornuda de Cástulo (Museo arqueológico de Cástulo. Dibujo:Aurrecoechea, 2001:159; fig. 64/7). (3) Hebilla cornuda del Collado de Los Jardines (Santa Elena) (Dibujo: Caballero, 1974:44; fig. 12/8.) 
p. 210). En los últimos trabajos de algunos autores como J. Aurrecoechea se plantea que los broches del grupo hispánico, al que pertenecen estas piezas, eran portadas fundamentalmente por individuos de la zona rural de la mitad norte peninsular que, quizás, formarían parte de la guardia personal de los dominus de las grandes Villas. Está hipótesis se justifica principalmente por la presencia casi exclusiva de estos broches en las necrópolis septentrionales del mundo rural peninsular (Aurrecoechea, 2009: p. 493, fig. 3).

Por otro lado, no hay duda de que los broches y elementos de cinturón del grupo pseudohispano y no-hispano son portados por los funcionarios y militares del ejército romano, por lo que la presencia de los mismos determina la presencia de tropas regulares o de funcionarios (Aurrrecoechea, 2009: p. 217) ahora con un fuerte sesgo militar (Arce, 1997: p. 55).

Sin embargo, la presencia de broches de tipo hispanos en Cástulo se desvía de esa idea, tanto por su hallazgo urbano como por su localización geográfica meridional. A estas piezas debemos añadir otra hebilla cornuda ${ }^{2}$ (Aurrecoechea; 2001: p. 91 y 92), ésta hallada en el denominado Collado de los jardines en Santa Elena (Jaén) (fig. 3) donde los últimos estudios determinan la existencia de un asentamiento fortificado que controlaba el paso de comunicación entre el Alto Guadalquivir y la meseta con indicios de hábitat hasta bien entrado el s. IV (Gutiérrez et alli, 2009: p. 357). La situación no rústica de estos broches nos hizo considerar si su situación era algo anecdótico y singular en relación con su ubicación excéntrica de los lugares normales de hallazgo o, por el contrario, estaba relacionada con alguna pauta más general.

Tabla 2. Broches y elementos de cinturón bajo imperiales hallados en yacimientos peninsulares Fuente principal Aurrecoechea, 2001, junto con nuevos hallazgos rastreados en publicaciones posteriores (sólo se han ubicado los elementos con contextualizaciones ciertas y uno por cada conjunto de elementos que forman un cinturón).

\begin{tabular}{|c|l|l|l|c|}
\hline ELEMENTO & TIPOLOGÍA & GRUPO & \multicolumn{1}{|c|}{ UBICACIÓN } & $\begin{array}{c}\text { TIPO DE } \\
\text { YACIMENTO }\end{array}$ \\
\hline Broche & Simancas & Hispano & Penadominga (Lugo) & Castro \\
\hline Broche & Simancas & Hispano & $\begin{array}{l}\text { Castillo de Carpio Bernardo } \\
\text { (Villagonzalo de Tormes, Salamanca) }\end{array}$ & Castro \\
\hline Placa & Simancas & Hispano & Vega de Seseña (Toledo) & Castro \\
\hline Placa & Simancas & Hispano & Castro de Viladonga (Lugo) & Castro \\
\hline Broche & Simancas & Hispano & Penadominga (Lugo) & Castro \\
\hline Broche & Complutum & Hispano & $\begin{array}{l}\text { Dehea de la Oliva (Torrelaguna, } \\
\text { Madrid) }\end{array}$ & Castro \\
\hline Broche & Cabriana & Hispano & Vera de Moncayo (Zaragoza) & Cueva \\
\hline Hebilla & En D & Hispano & $\begin{array}{l}\text { Cueva del Pany (Pontons, Vilafranca del } \\
\text { Penedés, Barcelona) }\end{array}$ & Necópolis \\
\hline Broche & Simancas & Hispano & Fuenteespreada (Zamora) Tumba 1 & Necrópolis \\
\hline Broche & Simancas & Hispano & Fuenteespreada (Zamora) Tumba 1 & Urbano/Necrópolis \\
\hline Broche & Simancas & Hispano & La Morterona (Saldaña, Palencia) & Urbano/Necrópolis \\
\hline Placa & Simancas & Hispano & La Morterona (Saldaña, Palencia) & Necrópolis \\
\hline Broche & Simancas & Hispano & $\begin{array}{l}\text { Villa de Olmeda (Pedrosa de La Vega, } \\
\text { Palencia) (Tumba 26) }\end{array}$ & Necrópolis \\
\hline Broche & Cabriana & Hispano & Cabriana (Burgos) &
\end{tabular}

2 No hemos incluido el broche de cinturón localizado en Mengíbar (Jaén) por su posible reutilización en épocas visigodas (Aurrecoechea 2001; pág. 101). 


\begin{tabular}{|c|c|c|c|c|}
\hline ELEMENTO & TIPOLOGÍA & GRUPO & UBICACIÓN & $\begin{array}{c}\text { TIPO DE } \\
\text { YACIMENTO }\end{array}$ \\
\hline Hebilla & En D & Hispano & $\begin{array}{l}\text { Villa de Olmeda (Pedrosa de La Vega, } \\
\text { Palencia) (Tumba 51) }\end{array}$ & Necrópolis \\
\hline Broche & Bienvenida & Hispano & Soto de Tovilla (Tudela de Duero) & Necrópolis \\
\hline Broche & Simancas & Hispano & La Nuez de Abajo (Burgos) & Necropolis \\
\hline Broche & Simancas & Hispano & Simancas (Valladolid) (Tumba 52) & Necrópolis \\
\hline Broche & Simancas & Hispano & Hornillos del Camino (Burgos) & Necrópolis \\
\hline Broche & Simancas & Hispano & Simancas (Valladolid) Tumba 133 & Necrópolis \\
\hline Broche & Simancas & Hispano & Valladolid & Necrópolis \\
\hline Hebilla & Rectangular & Hispano & Simancas (Valladolid) Tumba 46 & Necrópolis \\
\hline Hebilla & Rectangular & Hispano & Simancas (Valladolid) Tumba 36 & Necrópolis \\
\hline Hebilla & Cornuda & Hispano & $\begin{array}{l}\text { Collado de Los Jardines (Santa Elena, } \\
\text { Jaén) }\end{array}$ & $\begin{array}{l}\text { Poblado } \\
\text { (Santuario) }\end{array}$ \\
\hline Placa & Cabriana & Hispano & $\begin{array}{l}\text { Monte Mózinho (Oldroes, Penafiel, } \\
\text { Portugal) }\end{array}$ & Poblado fortificado \\
\hline Broche & Simancas & Hispano & La Morterona (Saldaña, Palencia) & $\begin{array}{l}\text { Poblado y } \\
\text { necrópolis }\end{array}$ \\
\hline Broche & Simancas & Hispano & Carpio del Tajo (Toledo) & Desconocido \\
\hline Broche & Simancas & Hispano & El Castillo (Soria) & Desconocido \\
\hline Hebilla & Cornuda & Hispano & Carpio del Tajo (Toledo) & Desconocido \\
\hline Hebilla & Cornuda & Hispano & Santo Tomé del Puerto (Segovia) & Desconocido \\
\hline Placa & Simancas & Hispano & Carpio del Tajo (Toledo) & Desconocido \\
\hline Broche & Cabriana & Hispano & $\begin{array}{l}\text { Las Murallas (Huertas de Abajo, } \\
\text { Burgos) }\end{array}$ & Desconocido \\
\hline Hebilla & Cornuda & Hispano & Puebla de Montalbán (Toledo) & Superficial \\
\hline Placa & Simancas & Hispano & Villasequilla de Yepes (Toledo) & Superficial \\
\hline Placa & Villasequilla & Hispano & Villasequilla de Yepes (Toledo) & Superficial \\
\hline Broche & Bienvenida & Hispano & Mengibar (Jaén) & Superficial \\
\hline Broche & Bienvenida & Hispano & Ocaña (Toledo) & Superficial \\
\hline Placa & Bienvenida & Hispano & Almendros (Cuenca) & Superficial \\
\hline Placa & Bienvenida & Hispano & Puebla de Montalbán (Toledo) & Superficial \\
\hline Placa & Bienvenida & Hispano & Villasequilla de Yepes (Toledo) & Superficial \\
\hline Hebilla & En D & Hispano & Borox (Toledo) & Superficial \\
\hline Hebilla & Cornuda & Hispano & Cástulo (Linares Jaén) & Urbano \\
\hline Hebilla & Cornuda & Hispano & $\begin{array}{l}\text { Arcóbriga Cerro del Villar (Monreal de } \\
\text { Ariza, Zaragoza) }\end{array}$ & Urbano \\
\hline Hebilla & Cornuda & Hispano & $\begin{array}{l}\text { Arcóbriga Cerro del Villar (Monreal de } \\
\text { Ariza, Zaragoza) }\end{array}$ & Urbano \\
\hline Hebilla & Cornuda & Hispano & Palencia & Urbano \\
\hline Hebilla & Cornuda & Hispano & Huete (Cuenca) & Urbano \\
\hline Broche & Cabriana & Hispano & Lugo (Lucus) & Urbano \\
\hline Hebilla & En D & Hispano & Astórga (León) Astúrica Augusta & Urbano \\
\hline Hebilla & En D & Hispano & Astórga (León) Astúrica Augusta & Urbano \\
\hline Placa & Bienvenida & Hispano & $\begin{array}{l}\text { La Bienvenida (Almodovar del Campo, } \\
\text { Ciudad Real) }\end{array}$ & Urbano \\
\hline Broche & Complutum & Hispano & Complutum (Alcala de Henares) & Urbano \\
\hline Broche & Simancas & Hispano & Cástulo (Linares Jaén) & Urbano \\
\hline Placa & Simancas & Hispano & $\begin{array}{l}\text { Carretera de San martín de Ampurias } \\
\text { (Gerona) }\end{array}$ & Vertedero \\
\hline
\end{tabular}




\begin{tabular}{|c|c|c|c|c|}
\hline ELEMENTO & TIPOLOGÍA & GRUPO & UBICACIÓN & $\begin{array}{c}\text { TIPO DE } \\
\text { YACIMENTO }\end{array}$ \\
\hline Hebilla & En D & Hispano & Liédena (Navarra) & Villa \\
\hline Broche & Bienvenida & Hispano & El quinto de la Hélice (Seseña, Toledo) & Villa \\
\hline Broche & Simancas & Hispano & Villarrubia de Santiago (Toledo) & Villa/Necrópolis \\
\hline Hebilla & Cornuda & Hispano & Villarrubia de Santiago (Toledo) & Villa/Necrópolis \\
\hline Hebilla & Cornuda & Hispano & Totanés (Toledo) & Villa/Necrópolis \\
\hline Placa & Bienvenida & Hispano & Totanés (Toledo) & Villa/Necrópolis \\
\hline Hebilla & En D & Hispano & Villarrubia de Santiago (Toledo) & Villa/Necrópolis \\
\hline Hebilla & En D & Hispano & Totanés (Toledo) & Villa/Necrópolis \\
\hline Trabilla & $\begin{array}{l}\text { Tipo A de } \\
\text { Bhöme }\end{array}$ & No-Hispano & El Roc d Enclar (Andorra) & Castellum \\
\hline Broche & $\begin{array}{c}\text { Tipo } 3 \text { b de } \\
\text { Sommer } \\
\text { (delfiniforme } \\
\text { con arquería) }\end{array}$ & No-Hispano & Palacios de Sil (León) & Castro \\
\hline Aplique & $\begin{array}{c}\text { Trier-Muri } \\
\text { de Bhöme } \\
\text { variante }\end{array}$ & No-Hispano & $\begin{array}{l}\text { Castro ventosa (Pieros, Cacabelos, } \\
\text { León) }\end{array}$ & Castro \\
\hline Hebilla & Zoomorfa & No-Hispano & Zuheros (Córdoba) & Cueva \\
\hline Hebilla & Trier-Muri & No-Hispano & Hornillos del Camino (Burgos) & Necrópolis \\
\hline Broche & $\begin{array}{l}\text { tipo A de } \\
\text { bhöme }\end{array}$ & No-Hispano & Hornillos del Camino (Burgos) & Necrópolis \\
\hline Contraplaca & $\begin{array}{l}\text { tipo B de } \\
\text { bhöme }\end{array}$ & No-Hispano & Pompaelo, Pamplona & Necrópolis \\
\hline Hebilla & $\begin{array}{l}\text { Verigenstadt } \\
\text { de Bhöme }\end{array}$ & No-Hispano & Hornillos del Camino (Burgos) & Necrópolis \\
\hline Hebilla & Zoomorfa & No-Hispano & Simancas (Valladolid) (Tumba 141) & Necrópolis \\
\hline Contraplaca & $\begin{array}{c}\text { Tipo B de } \\
\text { Bhöme }\end{array}$ & No-Hispano & La Morterona (Saldaña, Palencia) & Urbano/necrópolis \\
\hline Remate & $\begin{array}{c}\text { Tipo Ba de } \\
\text { Sommer } \\
\text { ánfora }\end{array}$ & No-Hispano & Mazarambroz (Toledo) & Desconocido \\
\hline Remate & $\begin{array}{l}\text { Tipo Bb de } \\
\text { Sommer } \\
\text { ánfora }\end{array}$ & No-Hispano & Palencia & Desconocido \\
\hline Hebilla & Zoomorfa & No-Hispano & $\begin{array}{l}\text { Monsanto (Idanha a Nova, Castelo } \\
\text { Branco, Portugal) }\end{array}$ & Desconocido \\
\hline Contraplaca & $\begin{array}{l}\text { Tipo A de } \\
\text { Bhöme }\end{array}$ & No-Hispano & Paredes de Navas (Palencia) & Urbano \\
\hline Contraplaca & $\begin{array}{l}\text { Tipo A de } \\
\text { Bhöme }\end{array}$ & No-Hispano & Paredes de Navas (Palencia) & Urbano \\
\hline Contraplaca & $\begin{array}{l}\text { Tipo A de } \\
\text { Bhöme }\end{array}$ & No-Hispano & $\begin{array}{l}\text { Villa de Olmeda (Pedrosa de La Vega, } \\
\text { Palencia) }\end{array}$ & Villa/Necrópolis \\
\hline Contraplaca & $\begin{array}{l}\text { Tipo A de } \\
\text { Bhöme }\end{array}$ & No-Hispano & $\begin{array}{l}\text { Villa de Olmeda (Pedrosa de La Vega, } \\
\text { Palencia) }\end{array}$ & Villa/Necrópolis \\
\hline Aplique & $\begin{array}{c}\text { Trier-Muri } \\
\text { de Bhöme } \\
\text { variante }\end{array}$ & No-Hispano & Pamplona & Urbano \\
\hline Hebilla & Zoomorfa & No-Hispano & $\begin{array}{l}\text { La Bienvenida (Almodovar del Campo, } \\
\text { Ciudad Real) }\end{array}$ & Urbano \\
\hline
\end{tabular}




\begin{tabular}{|c|c|c|c|c|}
\hline ELEMENTO & TIPOLOGÍA & GRUPO & UBICACIÓN & $\begin{array}{c}\text { TIPO DE } \\
\text { YACIMENTO }\end{array}$ \\
\hline Hebilla & $\begin{array}{c}\text { Tipo Cd6 } \\
\text { Clase } 1 \text { de } \\
\text { Sommer } \\
\text { delfiniforme }\end{array}$ & No-Hispano & Iruña (Trespuentes, Villodas) & Urbano fortificado \\
\hline Hebilla & Zoomorfa & No-Hispano & Can Bosch de Basea (Tarrasa) & Villa \\
\hline Aplique & Hélice & No-Hispano & Villarrubia de Santiago (Toledo) & Villa/Necrópolis \\
\hline Remate & $\begin{array}{l}\text { Tipo Bb de } \\
\text { Sommer } \\
\text { ánfora }\end{array}$ & No-Hispano & Villarrubia de Santiago (Toledo) & Villa/Necrópolis \\
\hline Remate & $\begin{array}{l}\text { Tipo } 2 \text { de } \\
\text { Bhöme }\end{array}$ & No-Hispano & Villarrubia de Santiago (Toledo) & Villa/Necrópolis \\
\hline Remate & $\begin{array}{l}\text { Tipo } 2 \text { de } \\
\text { Bhöme }\end{array}$ & No-Hispano & Villarrubia de Santiago (Toledo) & Villa/Necrópolis \\
\hline Placa & $\begin{array}{c}\text { Tongern- } \\
\text { Wessling de } \\
\text { Bhöme } \\
\end{array}$ & No-Hispano & Totanés (Toledo) & Villa/Necrópolis \\
\hline Aplique & $\begin{array}{c}\text { Tongern- } \\
\text { Wessling de } \\
\text { Bhöme }\end{array}$ & No-Hispano & Totanés (Toledo) & Villa/Necrópolis \\
\hline Hebilla & Zoomorfa & No-Hispano & Villarrubia de Santiago (Toledo) & Villa/Necrópolis \\
\hline Hebilla & Zoomorfa & No-Hispano & Les Colomines (Llivia, Gerona) & Castro \\
\hline Broche & $\begin{array}{c}\text { Tirig } \\
\text { (delfiniforme } \\
\text { con arquería) }\end{array}$ & Pseudohispano & $\begin{array}{l}\text { Castro de yecla (Sto Domingo de Silos, } \\
\text { burgos) }\end{array}$ & Castro \\
\hline Broche & $\begin{array}{c}\text { Tirig } \\
\text { (delfiniforme } \\
\text { con arquería) }\end{array}$ & Pseudohispano & Tirig (Cástellón) & Necrópolis \\
\hline Broche & $\begin{array}{l}\text { San miguel } \\
\text { (hebilla } \\
\text { trapezoidal y } \\
\text { arquería) }\end{array}$ & Pseudohispano & San Miguel del Arroyo (Valladolid) & Necrópolis \\
\hline Placa & $\begin{array}{c}\text { Tirig } \\
\text { (arquería) }\end{array}$ & Pseudohispano & Toledo & Desconocido \\
\hline Broche & $\begin{array}{l}\text { Santomé } \\
\text { (ánfora) }\end{array}$ & Pseudohispano & Burgos & Desconocido \\
\hline Placa & Borox & Pseudohispano & Borox (Toledo) & Superficial \\
\hline Placa & Borox & Pseudohispano & Ocaña (Toledo) & Superficial \\
\hline Broche & $\begin{array}{l}\text { Tipo Paredes } \\
\text { de Navas } \\
\text { (hebilla } \\
\text { trapezoidal y } \\
\text { arquería) }\end{array}$ & Pseudohispano & Paredes de Navas (Palencia) & Superficial \\
\hline Placa & $\begin{array}{c}\text { Tirig } \\
\text { (arquería) }\end{array}$ & Pseudohispano & Liédena (Navarra) & Villa \\
\hline Broche & $\begin{array}{c}\text { Totanes } \\
\text { (delfiniforme } \\
\text { con circulos) }\end{array}$ & Pseudohispano & Totanés (Toledo) & Villa/Necrópolis \\
\hline Placa & $\begin{array}{l}\text { Santomé } \\
\text { (caballo) }\end{array}$ & Pseudohispano & $\begin{array}{l}\text { Santomé (San bernardo de Tibiás, } \\
\text { Orense) }\end{array}$ & Castro \\
\hline Placa & Borox & Pseudohispano & Villarrubia de Santiago (Toledo) & Villa/Necrópolis \\
\hline
\end{tabular}




\begin{tabular}{|c|c|c|l|c|}
\hline ELEMENTO & TIPOLOGÍA & \multicolumn{1}{|c|}{ GRUPO } & \multicolumn{1}{|c|}{ UBICACIÓN } & $\begin{array}{c}\text { TIPO DE } \\
\text { YACIMENTO }\end{array}$ \\
\hline Aplique & Hélice & Pseudohispano & Totanés (Toledo) & Villa/Necrópolis \\
\hline Aplique & Hélice & Pseudohispano & Villarrubia de Santiago (Toledo) & Villa/Necrópolis \\
\hline Aplique & Hélice & Pseudohispano & Titulcia (Madrid) & Villa/Necrópolis \\
\hline Contraplaca & $\begin{array}{c}\text { Tipo A de } \\
\text { Bhöme }\end{array}$ & Pseudohispano & Villarrubia de Santiago (Toledo) & Villa/Necrópolis \\
\hline Hebilla & Delfiniforme & $\begin{array}{c}\text { Pseudohispano/ } \\
\text { No-Hispano }\end{array}$ & $\begin{array}{l}\text { Castillo Billido (Santa María de las } \\
\text { Hoyas, Soria) }\end{array}$ & Villa \\
\hline Hebilla & Delfiniforme & $\begin{array}{c}\text { Pseudohispano/ } \\
\text { No-Hispano }\end{array}$ & Sant Josep (Cástellón) & Villa \\
\hline Hebilla & Delfiniforme & $\begin{array}{c}\text { Pseudohispano/ } \\
\text { No-Hispano }\end{array}$ & $\begin{array}{l}\text { Villa de Olmeda (Pedrosa de La Vega, } \\
\text { Palencia) }\end{array}$ & Villa \\
\hline Hebilla & Delfiniforme & $\begin{array}{c}\text { Pseudohispano/ } \\
\text { No-Hispano }\end{array}$ & Can Bosch de Basea (Tarrasa) \\
\hline Hebilla & Delfiniforme & $\begin{array}{c}\text { Pseudohispano/ } \\
\text { No-Hispano }\end{array}$ & Torre Llauder (Mataró, Barcelona) & Villa destruida \\
\hline Hebilla & Delfiniforme & $\begin{array}{c}\text { Pseudohispano/ } \\
\text { No-Hispano }\end{array}$ & Villarrubia de Santiago (Toledo) & Villa Necrópolis \\
\hline
\end{tabular}

De esta manera, un examen de las procedencias de la población conocida de elementos de cinturones del grupo hispano ${ }^{3}$ nos permitió observar que una tercera parte de los mismos han sido recogidos en urbes o asentamientos de tipo castro (tabla 2). Aún más, dos hebillas de tipo cabriana (del grupo hispano) fueron halladas en Astúrica Augusta (Astorga, León) ciudad en la que no se duda de que en el bajo imperio albergó una guarnición de ejército romano (Morillo; 2003: p. 105; Morillo y Martín, 2005: p. 188) y otro broche también de tipo cabriana ha sido hallado en Lucus Augusti (tabla 2), ciudad en la que se sabe por la Notitia Dignitatum que en el S. IV tenía su sede la cohorte Lucensis.

Por otro lado, en varias necrópolis del centro y norte peninsular como Hornillo del Camino en Burgos, La Olmeda en Palencia o Villarrubia de Santiago en Toledo se han encontrado enterramientos con broches de tipo hispanos junto con enterramientos con broches del grupo no hispanos y pseudohispanos (tabla 2). Estos últimos, de innegable carácter militar, que si bien muestran rituales diferentes no tiene que significar obligatoriamente la pertenencia a distintos grupos sociales (Aurrecoechea, 2007a: p. 444) ya que estas diferencias podrían corresponder a distinciones de origen cultural de los soldados que integraban el ejército en esos momentos (soldados romanos cristianos, soldados germanos paganos, etc.) (Domínguez, 1983: p. 117). De esta manera, el hallazgo simultáneo de los dos grupos de broches y elementos de cinturón, no sólo se han verificado en las necrópolis de las villas sino que también se han encontrado en ámbitos urbanos como el yacimiento de La Bienvenida la antigua Sisapo en Ciudad Real. Entendemos que estos ejemplos matizan y difuminan esa marcada línea que define el último trabajo de J. Aurrecoechea entre el carácter paramilitar rural de los individuos que portaban los broches del grupo hispano de aquellos relacionados con la administración y el estamento militar romano, portadores de los broches de tipo pseudohispano y no-hispano.

3 El cuadro resultante se ha basado fundamentalmente en el excelente trabajo del Dr. D. Joaquín Aurrecoechea Los Cinturones romanos en la Hispania del bajo Imperio, Monographies instrumentos, 19, junto con algunas publicaciones esporádicas que hemos podido rastrear de los últimos hallazgos sobre este tipo de elementos. 
Por último, en algunos asentamientos como el de Villasequiya de Yepes (Toledo), aunque sólo se constatan broches de tipo hispánico, se sabe de la presencia de ejército regular en época alto imperial en el lugar a través de la existencia de hebillas de tipo peltiformes (Aurrecoechea, 1995/1996, figs. 1, 5).

Todos estos datos nos han hecho considerar la posibilidad de que los broches del grupo hispánico sean parte de la indumentaria del ejército regular romano de la península ibérica en el bajo imperio y, por tanto, que la presencia de este tipo de broches indican el estacionamiento de contingentes militares en las zonas en las que aparecen.

Esta misma hipótesis, entre otras ${ }^{4}$, es considerada por Paz Peralta (2002: pp. 60 a 62) ante el hallazgo de un broche tipo Simancas en un asentamiento de tipo castro en la partida de Maderuela (Vera del Moncayo, Zaragoza) que por su ubicación topográfica pudo estar relacionado con el control de caminos secundarios por un destacamento de tropas.

\section{CONTEXTO PRODUCTIVO DE LOS BROCHES HISPANOS}

Entendemos que la situación regional política y cultural de Hispania en relación con el imperio imprimió al ejército allí acantonado un carácter peculiar que explica el origen y desarrollo de los broches de cinturón hispanos dentro del seno del ejército del S. IV.

Con el definitivo asentamiento de la legio VII Gemina en Hispania en el 74 d.C. los integrantes del ejército se encuentran en un territorio alejado de los principales frentes de operaciones bélicas y donde las provincias estaban plenamente integradas en el imperio romano. La pacificación del territorio y el aislamiento de las zonas conflictivas del imperio hacía innecesaria una cantidad elevada de soldados, por lo que los efectivos militares eran menores que en otras zonas. Esta misma situación permitió un cierto aislamiento del ejército hispano con respecto a las demás unidades del imperio, puesto que no era necesario llevar tropas de refuerzo a una zona que estaba plenamente pacificada (Andrés, 2005: p. 414). De la misma manera, salvo contadas excepciones (Palao, 1998: p. 88), las tropas hispanas apenas tuvieron misiones fuera de la península. Por último, a partir del S. II, la mayoría de los integrantes del ejército hispano procedían de la propia península, por la tendencia a renovar efectivos en los mismos lugares donde se asentaba la legión, por lo que también contribuyó a potenciar aún más este aislamiento (Andrés, 2005, p. 421).

La función defensiva sólo fue requerida en casos muy excepcionales a lo largo del alto imperio, como la invasión de los mauri en el 172, siendo su función principal la relacionada con la buena administración de las provincias y la logística (policía, avituallamiento, vigilancia), según se desprende del trabajo de la investigadora Gloria Andrés (2005: p. 422).

Prácticamente la misma situación de paz y tranquilidad se suceden a lo largo del bajo imperio (Alonso-Núñez, 1990: p. 9; Arce, 2005: p. 199; Aurrecoechea, 2001: p. 212) y ni tan siquiera las grandes reformas militares ${ }^{5}$ de Diocleciano y Constantino afectaron de manera sustancial a las antiguas unidades del ejército alto imperial hispano ${ }^{6}$ (Palao, 1998: p. 113), que

\footnotetext{
4 También plantea la posibilidad de que sea un asentamiento de gentes marginales como los bagaudas.

5 Sólo se ha constatado la conversión del Ala II Flavia a Cohors II Flavia Pacatiana (Domínguez, 1983: 113)

6 En todo el trabajo cuando hablemos del ejército hispano sólo nos referiremos a las tropas acantonadas en la península desde el alto imperio, ya que las de tipo comitatenses que la notitia dignitatum menciona en territorio hispano, por su perfil de fuerzas de choque móviles tuvieron que ser ejércitos que se desplazaban por todo el imperio según sus necesidades defensivas, por lo que su estancia en Hispania debía ser corta, intermitente y coyuntural como plantea el profesor Javier Arce (1997: 72).
} 
siguen denominándose de la misma manera y ocupando los mismos acuartelamientos (Domínguez, 1983: p. 114).

En el mismo sentido, incide la forma de reemplazo de efectivos en las guarniciones hispanas que, como ya hemos comentado, desde el s. II se hacía mayoritariamente a través del reclutamiento local y que tuvo que agudizarse en el bajo imperio ya que a partir de la tetrarquía se obliga a los hijos de los veteranos a seguir los pasos de sus padres (Domínguez, 1983: p. 122; Cañizar, 1998: p. 220).

En definitiva, la tranquilidad de la que gozó la Península Ibérica entre los s. II y IV permitió la formación de un ejército bajo imperial caracterizado por estar integrado por una tropa prácticamente indígena. Esta tropa estaba alejada de los centros de decisión, pero también de los principales frentes de las operaciones bélicas (Andrés, 2005: p. 413), por lo que no tenía necesidades defensivas relevantes (Domínguez, 1983: p. 114). Su función habitual era la de policía, vigilancia, misiones de logística (Andrés, 2005: p. 25) y aquellas relacionadas con el officium de los administradores de las provincias (Palao, 1998: p. 158). Esta situación tuvo que hacer prácticamente innecesario el movimiento de nuevas tropas a la península, pero también provocó la ausencia de movimientos extrapeninsulares de las tropas hispanas. Esto último debido a factores tan importantes como la reducción de efectivos, su limitada capacidad de lucha y la misión que desempeñaba en el territorio debieron ser determinantes en la decisión de los emperadores de no moverlas. La consecuencia fue un «aislamiento» secular del grueso del ejército romano acantonado en Hispania a principios del s. IV, que además se habría agravado a mediados del s. III.

Efectivamente, durante los agitados años del s. III y, sobre todo, a partir del reinado de Galieno (253-268), la fuerte inestabilidad interna del Imperio y el aumento de sus problemas fronterizos dieron lugar a la obstaculización de las vías de distribución del equipo militar desde las fabricae imperiales hasta los campamentos de las tropas (de Francisco, 2011: p. 39). Esta situación contribuyó en gran parte al origen y desarrollo de los broches y apliques de los cingula militiae plenamente bajo imperiales del s. IV desde la evolución de los atalajes de los cinturones de las tropas auxiliares destacadas en los lugares conflictivos del imperio (Pérez, 1992: p. 241).

De esta forma, el ejército romano de Hispania se nos representa como una institución de una fuerte cultura militar endogámica, relacionada con las formas y actitudes típicas alto imperiales y, por consiguiente, retardataria. Las aisladas y autóctonas guarniciones hispanas se estuvieron rigiendo fundamentalmente durante varios siglos por los antiguos presupuestos culturales, estilísticos y tecnológicos del ejército alto imperial. Presupuestos que se retroalimentaban a lo largo del tiempo por la escasa o nula sustitución de cuadros de mandos y veteranos de otros lugares, que además en gran parte eran los padres de los nuevos reclutas por lo que el principio de autoridad pedagógica tenía un sólido componente psicológico positivo.

Consecuentemente, este carácter autóctono debió de influir fuertemente en la fabricación de gran parte de la militaria de los soldados, y en concreto la relacionada con su indumentaria personal como son los cingula militiae, como en otras partes del imperio, que se verá caracterizada por las formas y estilos atávicos. Esta situación parece confirmarse con los hallazgos en Hispania de broches de tipología alto imperial en contextos de la primera mitad del s. IV (Aurrecoechea, 2007a: p. 442).

La existencia de cierta falta de uniformidad en la indumentaria militar (de Francisco, 2011: p. 39), por la génesis de distintas modas castrenses según la ubicación y la idiosincrasia de los distintos ejércitos romanos, se debió ver potenciada en el s. IV por la división del poder imperial con la consecuente fragmentación de la autoridad a todo los niveles, el debilitamiento de la autoridad central y el aumento cada vez mayor del control por parte de la periferia (Arce, 2005: p. 53). 
Sin embargo, también es cierto, que para el estado romano era necesario y fundamental remarcar la identidad de sus soldados mediante señales externas homogéneas y estandarizadas relacionadas con la uniformidad que identificaran su estatus y autoridad (Aurrecoechea, 2001: p. 209) como emanación del poder que representaban. De esta forma, en el bajo imperio, el cingulum se convierte en parte esencial del uniforme y en una de las principales insignias oficiales símbolo de rango y de dignidad (Aurrecoechea, 2001: p. 207; Pérez, 1992: p. 239). Tanto es así que «la entrada en el servicio militar activo se designaba con los términos cingulum sumere o cingulum Mereri» (Aurrecoechea, 2001: p. 207). Pero en una sociedad tan militarizada como la romana del bajo imperio no valía esto solamente para la institución militar sino que la administración civil también se unía a esta imposición de tal forma que en palabras de Lactancio los funcionarios civiles constituían una militia non armata (Lact. De mortibus, 31).

El resultado de ambas tendencias se observa en el análisis estilístico de los broches y decoraciones de los cingula del bajo imperio donde las diferencias formales y decorativas entre los grupos se aglutinan a partir de una misma koiné bajo imperial (Aurrecoechea, 2001: p. 201), concretada por el control de la administración militar de dos factores: el acceso restringido de estos objetos a personal militar y funcionarial, y la determinación de ciertos parámetros físicos en la fabricación de los mismos, como lo demuestra la legislación romana sobre la regulación de sus decoraciones (Cod. Theod. XIV, 10 ,1).

Son desde todas las premisas anteriores desde donde se puede explicar de manera clara y razonada la existencia de los distintos grupos de los broches de cinturón bajo imperiales dentro de la esfera militar. De esta manera a partir de la segunda mitad del s. IV se aprecia la llegada a Hispania del equipo militar de la prefectura gala con la presencia de cinturones de hebilla delfiniforme y placa decorativa en opus interrasile (cinturones no hispanos) que supone la implantación de unas directrices comunes sobre los territorios que rige (Galia, Britania e Hispania). Estas directrices van a dar lugar a la creación de los broches de tipo pseudohispanos iguales a los no hispanos en cuanto a forma y decoración, pero que se diferencia en la forma de engarce al cuero por la existencia de roblones, técnica común en Hispania en esos momentos, en vez de remaches. Se puede decir que ambos tipos forman parte del mismo estilo universal y surgen de la subordinación incondicional a las directrices marcadas por los elementos de poder oficiales del la prefectura gala. No hay ninguna duda de que son los broches militares que portan tanto los funcionarios venidos del exterior de la provincia (no hispanos) como los funcionarios hispanos (pseudohispanos) (Aurrecoechea, 2001: p. 232).

Pero como decíamos anteriormente, la introducción de esta moda oficial no se hacía sobre un ambiente aséptico sino que se superponía a una fuerte corriente de fabricación y uso de equipamiento militar arcaico de fuerte arraigo en la aislada y autóctona tropa hispana.

De esta manera, es la conjunción de las dos tendencias anteriores la que da origen al grupo de broches hispanos como una moda regional militar. El caso de los broches de tipo Simancas es paradigmático, ya que los prototipos preexistentes de principios del s. IV se ven modificados por las decoraciones de los broches universales de la segunda mitad del s. IV (Aurrecoechea, 2009: p. 491). Es en estas influencias donde vemos una referencia clara y precisa a las prescripciones de la administración militar de la prefectura gala de ciertos parámetros físicos en la ejecución de los cingula. Entendemos, por tanto, que estos broches son de uso militar y que eran portados mayoritariamente por la tropa asentada en la península ibérica. La elección de este grupo de broches con evidentes elementos retardatarios, desdeñando los de carácter más oficial como los pseudohispanos o no-hispanos, estaría impulsada por profundos motivos sociales y psicológicos que seguidamente vamos a exponer.

El ejército puede entenderse como una «institución totalitaria» (Goffman, 1970: p. 18) caracterizada por ser lugar de residencia y de trabajo en el que un gran número de individuos 
en igual situación, se encuentran aislados de la sociedad durante amplios períodos de tiempo. Dichos individuos comparten en su encierro una rutina diaria, administrada formalmente. Pertenecer a una institución de este tipo implica eliminar cualquier rasgo de individualidad a favor de un sentimiento de identidad colectiva. Para ello, este tipo de organizaciones se valen de un mecanismo de socialización que implica una transformación absoluta de las personas que se integran en ella, el ejército genera su propio universo simbólico con objeto de transformar aspectos como la cultura, la interacción social, . . . a fin de crear un colectivo operativo y disciplinado, capaz de acometer los fines de dicha institución.

Uno de los elementos clave de cualquier institución de carácter militar es, sin duda, la extrema jerarquización de sus componentes, tanto a nivel colectivo (el rango de cada batallón), como a nivel individual (el rango de cada soldado). Este sistema jerárquico queda bien definido entre sus componentes mediante símbolos y códigos que poseen una doble función de comunicación y participación (nos permiten identificar el sentimiento de pertenencia a grupos o colectividades sociales). En este sentido, los elementos de la indumentaria que define los símbolos de sus unidades, en definitiva del grupo al que pertenecen, son fundamentales como elementos que aglutinan a los diferentes miembros y que los diferencia de los demás como hermanos en armas. A la llegada de la imposición de la prefectura gala los soldados hispanos, sobre todo los soldados de tropa, serán reacios a asimilar un símbolo que aunque de carácter universal militar oscurece el origen y gloria de sus unidades ancestrales, puesto que los broches de carácter retardatario son los elementos simbólicos que les identifican como parte de su unidad y los entronca con el orgullo de servir en una unidad de pasado ilustre donde también han servido sus antepasados. Por lo que el uso de estos elementos llevarían a un sentimiento de vinculación doble: por un lado, a la de su unidad actual, pero por otro lado, los enlazarían con sus progenitores que habían servido en las mismas guarniciones en los tiempos gloriosos del alto imperio. Les vincularían por tanto a sus familias al igual que a su unidad. Así, la importancia de portar esos elementos en sus cinturones de combate sería aún más transcendental desde sus conceptos simbólicos, al haberse convertido en el bajo imperio en los elementos alegóricos que representaban su autoridad militar.

Es más, es muy posible que la consolidación y desarrollo de los broches del grupo hispano esté relacionado con un movimiento de rechazo de los soldados hispano-romanos al proceso de «barbarización» del ejército de los emperadores del bajo imperio. Dicha «barbarización», es decir, el reclutamiento de efectivos bárbaros en las unidades regulares romanas, se convierte en un hecho normalizado desde el reinado de Constantino, dónde gran parte de las tropas ya son de cuño extranjero (Pérez y Viñe, 1989-1990: p. 255). Tal situación se debía a la dificultad en obtener reclutas en las levas internas por la renuencia de los ciudadanos romanos a ingresar en un ejército en constante lucha y peligro (Cañizar, 1998: pp. 222 a 225), caracterizado por un exceso de disciplina, un servicio riguroso, deficiente organización en el avituallamiento y común ubicación en lugares de climas extremos (Vallejo, 1993: p. 244). Desde ese momento los emperadores, debido a las acuciantes necesidades defensivas del imperio y las continuas bajas de las tropas por las frecuentes luchas en las que se ven envueltas, van a ir introduciendo cada vez más efectivos bárbaros en el ejército, ya que las levas en el seno de la población civil del imperio no tenían éxito. De esta manera, no es descabellado pensar que buena parte de los individuos que portaban los broches de hebilla delfiniforme del grupo no hispano fueran bárbaros e incluso en algunos casos oficiales (Aurrecoechea, 2001: p. 220). La presencia de estos individuos en los campamentos hispanos, integrada por tropa genuinamente romana, generaría recelos, envidias (Cañizar, 1998, p. 230) y un fuerte sentimiento de rechazo de la indumentaria que portaban, como ajena a las verdaderas señas de identidad del ejército romano. La reacción fue la consolidación voluntaria en la pieza determinante de su estatus de soldados, como es el 
cingulum militiae, de elementos claramente visibles de ascendencia alto imperial, que había sido práctica habitual hasta ese momento, para reivindicar su rancio abolengo de verdadero soldado romano sin olvidar que pertenecían y tenían que acatar las órdenes de la administración militar. El resultado sería la creación de los broches de tipo Simancas y Bienvenida que son los de creación más antigua (Aurrecoechea, 2001: pp. 232 y 233).

La intensificación de la barbarización del ejército en el último tercio del s. IV y los acontecimientos históricos ocurridos en la península ibérica a principios del s. V, explican la evolución y diferenciación de los broches de tipo Cabriana, Villasequilla y Complutum del grupo hispano de los excisos y troquelados de los no-hispano.

Está constatado que los broches excisos son piezas expresamente fabricadas por Valentiniano I para los que se ha venido en llamar «bárbaros imperiales» (Pérez y Viñe, 1989-1990: 96), pues desde este momento el ejército se compone mayoritariamente de bárbaros (Arce, 1997: p. 120). El hallazgo de este tipo de guarniciones en la Península Ibérica demuestra la llegada de cada vez más contingentes de tropas y oficiales bárbaros. Tal situación debió agravar el sentimiento de odio y rechazo de los soldados nativos hispano-romanos de esos cuerpos de ejército intrusos, como demuestra que gran parte de las deserciones de efectivos romanos en el ejército imperial fuera por la posibilidad de tener que compartir sus insignias con los que recientemente habían sido sus enemigos (Cañizar, 1998: p. 230). A principios del S. V esta situación empeoró por la llegada y confrontación en suelo hispano de tropas de carácter comitantense relacionadas con la usurpación de Constantino III y posteriormente con la invasión de la Península Ibérica por pueblos bárbaros como consecuencia de aquel acontecimiento 7 . Tropas que portaban los nuevos broches oficiales de tipo troquelado.

Es lógico pensar que ante estos acontecimientos la tropa nativa hispana intentara excluirse del ejército barbarizado foráneo reflejándolo en la producción evolucionada de los broches del grupo hispano hacia rasgos más regionalista (Cabriana, Villasequilla y Complutum) y donde primaban las formas y decoraciones con origen en piezas castrenses alto imperiales, las cuales eran diametralmente diferentes a las guarniciones de los cinturones de tipo exciso y troquelado. Con el uso de las nuevas producciones de cinturones y broches regionales, la tropa hispano romana expresaría la voluntaria exclusión para con las nuevas tropas bárbaras así como definirse como una unidad militar singular y cerrada entroncada legítimamente con el antiguo y verdadero ejército romano. Esta libertad en la fabricación de guarniciones de carácter regionalista, al margen de las de tipo oficial, se veía cada vez más potenciada por la cada vez mayor debilidad de la administración imperial a lo largo del s. IV que llegó a sus más altos niveles con el derrumbe organizativo de la prefectura gala por los acontecimientos bélicos de principios del s. V (Aurrecoechea, 2007a: p. 443) de tal manera que las unidades militares asentadas en territorio hispano tuvieron que disfrutar de mayores grados de libertad y de cierto carácter autárquico potenciado por los problemas de avituallamiento en una diócesis invadida por diferentes pueblos bárbaros, dando como resultado la producción de los nuevos modelos de cingula hispanos.

Quizás la falta de mención de fabricae armae en la diócesis hispaniarum por la Notitia Dignititatum puede esgrimirse como un hecho fundamental para plantear una producción ajena a la esfera militar de los broches de tipo Hispano. Sin embargo, los recientes hallazgos en la ciudad/campamento de León de talleres relacionados con la fabricación y reparación de militaria hasta finales del s. III (Aurrecoechea, 2007b: p. 175) constata la realidad de los escritos del s. IV de Vegecio (De rei militari II, 7) desde donde se deduce que los asentamientos militares podían funcionar como un centro productivo autónomo de efectos militares (Morillo, 2006: p. 64).

\footnotetext{
7 Nos referimos al pacto del General Gerontius con vándalos, suevos y alanos para que pudieran pasar a suelo hispano. (Hyd., 34).
} 
En definitiva, la existencia de estos talleres locales de índole militar dirigidos directamente por las unidades hispanas permite comprender la evolución del registro arqueológico de los broches hispanos. Primero con la perduración de efectos militares como los broches alto imperiales o las armaduras de tipo segmentata hasta fechas tan tardías como la primera mitad del s. IV (Aurrecoechea, 2007a: p. 442 y Aurrecoechea 2007b. p. 177), debido a la autoctonía de la tropa integrada en unidades de viejo cuño donde los problemas políticos y militares del s. III obstaculizaron las vías de distribución del equipo militar desde las fábricas imperiales (de Francisco: 2011: p. 39). Después con la aparición de los cinturones hispanos caracterizados por su composición mixta como resultado por un lado, de la necesidad de la administración romana de cierta estandarización en la uniformidad del ejército de elementos de carga simbólica y representativa tan importante como los cingula militiae y, por otro, de la delegación parcial de la realización de dichos elementos por parte de un estado romano cada vez más débil y menos centralizado en la segunda mitad del s. IV. Y, por último, ante el colapso de la administración central y periférica de la prefectura gala entre los s. IV y V, con producciones más regionalista donde prevalece y aumentan los estilos basados en los aspectos más arcaizantes, rechazando los cinturones de los equipamientos excisos y troquelados por proceder de tropas comitantenses barbarizadas y extrañas al mundo castrense hispano.

\section{DISTRIBUCIÓN TERRITORIAL DE LOS BROCHES Y FUNCIÓN DEL EJÉRCITO}

Como comentábamos al principio de este trabajo, la distribución de buena parte los broches de cinturón de tipo hispano en necrópolis ${ }^{8}$ y villas tardo hispanas es uno de los datos básicos por el cual se han caracterizado a las personas portadoras de este tipo de elementos como posibles integrantes de ejércitos privados de los grandes dominus de las villas, principalmente por la falta de hallazgos de estos broches en contextos militares claros y porque cuando se dan en una misma necrópolis enterramientos con broches de tipo hispano y broches de tipo no-hispano / pseudohispanos (militares) se aprecian ritos de inhumación diferentes (Aurrecoechea; 2007: p. 444). Aunque esto último se puede explicar por las diferencias de origen cultural y religioso de los componentes del ejército romano en el bajo imperio (romanos cristiano, bárbaros paganos, etc.) que aflorarían de manera significativa en el momento de la muerte del soldado (Domínguez, 1983: p. 117).

Pero a nuestro modo de ver, el solapamiento en la distribución de ambos grupos de broches en algunos yacimientos, tanto de ambiente rural como urbano permite pensar en la posibilidad de que ambos grupos sean parte de la misma realidad, esto es, el carácter militar de los portadores de estos cinturones hispanos toda vez que es indudable el carácter castrense de los broches pseudohispanos y no-hispanos.

Efectivamente, buena parte de las ubicaciones de los broches de cinturón de plena acepción militar en el territorio peninsular pueden ser explicadas a partir de la funcionalidad, o mejor dicho, de la misión encomendada al ejército hispano por parte del Imperio. De esta manera el solapamiento en la distribución de ambos grupos de broches nos lleva a la idea de que todos tienen el mismo carácter militar. También redunda en la misma idea las variadas ocasiones en que los hallazgos de broches hispanos aislados se vinculan a yacimientos de las misma características que las de los asentamientos donde se han encontrado los broches típicamente militares, por lo que la distribución global de ambos grupos de broche se complementa para

\footnotetext{
8 Fundamentalmente de la denominada Subcultura del Duero.
} 
reflejar de manera explicita la disposición del ejército hispano en relación con las funciones confiadas al ejército.

Las funciones dadas al ejército Bajo imperial en una Hispania pacífica no van a ser muy diferentes a las que ya tenía en fechas anteriores. Éstas se pueden resumir en labores de avituallamiento militar de ámbito regional, vigilancia, policía y colaboración en el oficcium de los altos funcionarios de las capitales de provincias (Arce, 1988: p. 73 Aurrecoechea, 2001: p. 214). Ahora bien, las nuevas necesidades geoestratégicas del imperio en relación con su defensa va a determinar que la recaudación, vigilancia y transporte de la annona militaris hacia los centros militares europeos sea la actividad primordial del ejército hispano (Fernández y Morillo 2002: p. 584; Morillo y Martín, 2005: p. 188).

Es con ese fin con el que se explican las transformaciones observadas en la península ibérica, relacionadas con una decidida política de adecuación y mejora de la red viaria en el s. IV (Solana y Sagredo; 1998: pp. 9 y ss. y 2006: pp. 47 a 52) y con un programa regional de fortificación urbana selectivo en donde se incluyen ciudades de pequeño y mediano tamaño como nudos principales de comunicación regionales sobre dichas vías (Fernández y Morillo, 1994: p. 189; y 1997: p. 739). Ambas acciones íntimamente imbricadas entre sí y relacionadas con una mayor solidez en la vertebración del territorio, de tal manera que el control y vigilancia de la annona por las vías fuera efectivo y que las ciudades fortificadas se convirtieran en un sistema de red de estaciones intermedias como infraestructura necesaria para recaudar, gestionar y controlar un tránsito fluido y constante de los avituallamientos, integrados en dicha annona, hacia los puntos de destino en el limes septentrional de imperio (Fernández y Morillo 2002: pp. 585 y 586; Morillo y Martín, 2005: p. 188). El registro arqueológico de esas ciudades fortificadas como Veleia demuestran la existencia de guarniciones militares en un momento en que la frontera entre la vida civil y militar desaparece de tal manera que los antiguos asentamientos campamentales se convierten en ciudades insertas en el nuevo sistema geoestratégico, como es el caso de León (Morillo y García, 2009: p. 400) por lo que se ha afirmado que la totalidad de las tropas destacadas en Hispania se encontraban distribuidas en ciudades (Fernández y Morillo, 1997: p. 737) y se estaban utilizando por el estado imperial como una pieza administrativa fiscal más (Fernández y Morillo, 2002: p. 584).

La distribución de los broches de cinturón en asentamientos ubicados sobre la importante vía XXXIV del Itinerario de Antonino De Hispania in Aequitania como Asturica Augusta (Astorga), Deobriga (Cabriana) o Pompaelo (Pamplona) que vertebra el Norte peninsular con la Galia o, lo que es lo mismo, el centro militar peninsular (Legio) con la capital de la prefectura (Augusta Treverorum a través de Burdigala) (lámina 1), y que se puede considerar una verdadera ruta annonaria (Fernández y Morillo; 1997: 740) refleja la presencia de guarniciones del ejército en el desempeño de las funciones logísticas encomendadas. No debe extrañar la presencia de guarniciones en stationes o mansio, del tipo de Deóbriga, puesto que la vigilancia, gestión y supervisión del transporte de la annona tenía que ir acompañado de un estrecho y directo control de las vías por las que debía pasar cuyo uso, además, estaba restringido por orden imperial (Arce, 1997: p. 128). Entendemos que sólo el control directo por parte de guarniciones militares establecidas en stationes o mansio estratégicas a lo largo de los itinerarios de las vías pueden explicar que pudiera ejecutarse la multa al mismísimo Vicarius Hispaniarium Macrobius por utilizarlas, sin permiso imperial, en su provecho, o la utilización de las mismas por los agentes de Symmaco para trasladar caballos después de tener en regla los permisos necesarios (en Arce, 1997: 128). Además, esta ocupación de stationes y mansio por parte del ejército no era una práctica nueva puesto que en lo siglos del alto imperio ya se constata la presencia del ejército en dichos asentamientos llevando a cabo las mismas funciones (Andrés, 2005: p. 422) que en estos momentos se hacen fundamentales. 


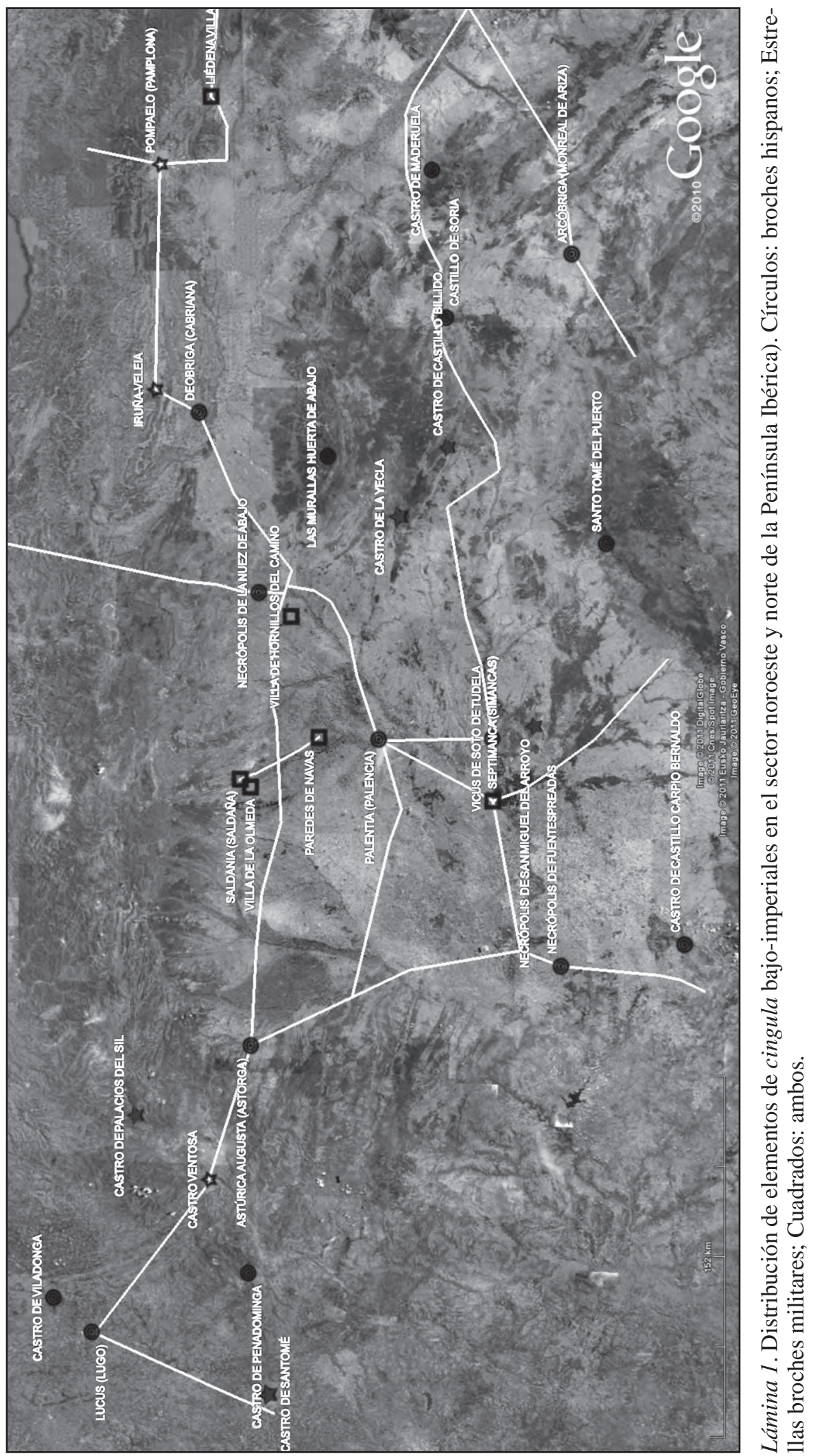

Gladius, XXX XIII (2013), pp. 81-112. ISSN : 0436-029X . doi: 10.3989/gladius.2013.0004 
De esta manera consideramos los asentamientos sobre las vías donde se han hallado broches de cinturón del objeto de nuestro estudio como yacimientos de tipo statio, mansio o mutatio. Entendemos que la falta de asignación de dichos asentamientos a estaciones viarias se debe a una falta de análisis de las características específicas de este tipo de yacimientos (Núñez y Sáenz, 2005: p. 198), puesto que es menos problemático para los excavadores definirlas con el concepto genérico de villas o incluso vicus que intentar precisar los crípticos elementos caracterizadores de su función logística. Sin embargo, aunque las villas se instalaban en las cercanías de las vías para poder comercializar sus productos, no se edificaban sobre las calzadas (Hurtado, 1999: p. 396) para evitar engorrosas obligaciones de servicios estatales o problemas relacionados con el tránsito de viajeros.

Pero en la distribución de unidades militares y, por ende, de los broches de cinturón tuvo que jugar un papel destacado la función policial de las mismas. Sobre todo en relación con la protección contra bandas de ladrones y salteadores, cuyo lugar de operaciones se encontraba normalmente en los agrestes y despoblados saltus. La eficiencia en el control de las actividades de estos salteadores y la vigilancia de los terrenos donde se ocultaban tenía que estar apoyada por un sistema de pequeños núcleos fortificados o castros, ubicados en lugares estratégicos dentro o a las salidas de los saltus donde asentar guarniciones, como parece confirmarlo la presencia de broches de cinturón en yacimientos como los castros de Yecla (Burgos) o Castillo Billido (Soria) (Aurrecoechea, 2001: pp. 72 y 76).

Por último, no podemos olvidar los trabajos relacionados con el apoyo a las autoridades provinciales que requería la presencia de efectivos en los centros administrativos más importantes de la provincia. Ejemplo es el hallazgo de un broche en Mérida (Aurrecoechea, 2001: p. 236).

\section{III.1. AproXimaCiÓN CUANTITATIVA DE LA DISTRIBUCIÓN DE LOS BROCHES}

Los ejemplos anteriormente citados sobre el hallazgo de broches de cinturón explican la presencia y distribución del ejército según las distintas misiones que debían realizar en suelo peninsular. Sin embargo, esos ejemplos son casos concretos que pueden ser desviaciones de la tendencia general en la distribución de los broches, por lo que la realidad podría ser diferente a la relación que hemos propuesto. Conscientes de la posibilidad de error en nuestra hipótesis hemos realizado un análisis estadístico sobre la significación positiva de la distribución de los broches en relación con la funcionalidad que se ha planteado para las tropas hispanas.

Para llevar a cabo este análisis hemos seleccionado el sector norte peninsular por cuatro motivos fundamentales:

1. Este sector es en el que se acepta, sin ninguna duda, la presencia del ejército hispano como lugar central de operaciones, por lo que la presencia de militaria en los yacimientos no genera prevención en su uso militar.

2. Es en este sector donde el análisis de la trayectoria exacta de las vías romanas está más avanzado, por lo que se puede determinar con bastante precisión si los yacimientos estudiados están sobre las vías o fuera de las mismas.

3. Además esta región se ha definido como clave en la gestión y trasporte de la annona militar (Fernández y Morillo, 1997: p. 739) y, por tanto, lugar donde el ejército habría incidido en la organización de su gestión de manera más palpable.

4. Es el lugar donde se incluye las necrópolis de la subcultura del Duero que ha sido relacionada con los broches de cinturón hispano y su uso por parte de grupos paramilitares 
de ámbito rústico. La situación central de esta región en la explicación cultural paramilitar de los broches hispanos la hace objetivo prioritario para analizar si la distribución de los mismos se acerca más a las condiciones tradicionales o se relacionan mejor con lugares donde prevalece las premisas relacionadas con la funcionalidad policial y control y vigilancia de las vías romanas propias del ejército regular.

En este sentido, hemos tenido en cuenta dos tipos de localizaciones, aquellas que estaban relacionadas con la funcionalidad del ejército, por lo que la presencia de guarniciones militares sería esperada (castros, urbes y asentamientos que se encuentran sobre vías) y aquellas que estuvieran vinculadas al medio agrario (villas o asentamientos no definidos).

En este caso, utilizamos el test no paramétrico de Chi Cuadrado mediante el paquete estadístico SPSS ya que las variables son nominales y las frecuencias esperadas son, en todos los casos, mayores a 5. Nuestra hipótesis nula sería aquella que demuestra que la ubicación de los broches se debe exclusivamente al azar, mientras que la hipótesis alternativa reflejaría una clara relación estadística en cuanto a la ubicación de los broches en localizaciones funcionalmente militares.

El universo de estudio contaba con 14 broches para los de tipo no hispano/pseudohispano (militares) (11 ubicados en localizaciones funcionalmente militares y 3 ubicados en localizaciones rústicas) y de 21 para los hispanos (de éstos, 16 se ubican en localizaciones militares y 5 en rústicas) (tabla 3 ).

Tabla 3. Broches y elementos de cinturón bajo imperiales hallados en yacimientos del noroeste y norte peninsular.

\begin{tabular}{|c|c|c|}
\hline UBICACIÓN & $\begin{array}{l}\text { GRUPO DE LOS } \\
\text { BROCHES }\end{array}$ & TIPO DE YACIMENTO \\
\hline $\begin{array}{l}\text { Castillo de Carpio Bernardo (Villagonzalo de Tormes, } \\
\text { Salamanca) }\end{array}$ & Hispano & Castro \\
\hline Castro de Viladonga (Lugo) & Hispano & Castro \\
\hline Penadominga (Lugo) & Hispano & Castro \\
\hline Vera de Moncayo (Zaragoza) & Hispano & Castro \\
\hline Fuenteespreada (Zamora) & Hispano & Yacimiento sobre vía \\
\hline La Morterona (Saldaña, Palencia) & Hispano & $\begin{array}{l}\text { Yacimiento sobre vía (urbano/ } \\
\text { Necrópolis) }\end{array}$ \\
\hline Villa de Olmeda (Pedrosa de La Vega, Palencia) & Hispano & Villa/Necrópolis \\
\hline Cabriana (Burgos) & Hispano & Yacimiento sobre vía \\
\hline Soto de Tovilla (Tudela de Duero) & Hispano & Yacimiento sobre vía \\
\hline La Nuez de Abajo (Burgos) & Hispano & Yacimiento sobre vía \\
\hline Simancas (Valladolid) (Tumba 52) & Hispano & Yacimiento sobre vía \\
\hline Hornillos del Camino (Burgos) & Hispano & Necrópolis \\
\hline El Castillo (Soria) & Hispano & Desconocido \\
\hline Santo Tomé del Puerto (Segovia) & Hispano & Desconocido \\
\hline Las Murallas (Huertas de Abajo, Burgos) & Hispano & Desconocido \\
\hline Arcóbriga Cerro del Villar (Monreal de Ariza, Zaragoza) & Hispano & Yacimiento sobre vía (urbano) \\
\hline Palencia & Hispano & Yacimiento sobre vía (urbano) \\
\hline Lugo (Lucus) & Hispano & Yacimiento sobre vía (urbano) \\
\hline Astórga (León) Astúrica Augusta & Hispano & Yacimiento sobre vía (urbano) \\
\hline Liédena (Navarra) & Hispano & Yacimiento sobre vía \\
\hline
\end{tabular}




\begin{tabular}{|c|c|c|}
\hline UBICACIÓN & $\begin{array}{l}\text { GRUPO DE LOS } \\
\text { BROCHES }\end{array}$ & TIPO DE YACIMENTO \\
\hline Palacios de Sil (León) & No-Hispano & Castro \\
\hline Castro ventosa (Pieros, Cacabelos, León) & No-Hispano & Yacimiento sobre vía \\
\hline Hornillos del Camino (Burgos) & No-Hispano & Necrópolis \\
\hline Pompaelo, Pamplona & No-Hispano & $\begin{array}{l}\text { Yacimiento sobre vía (urbano/ } \\
\text { Necrópolis) }\end{array}$ \\
\hline Simancas (Valladolid) (Tumba 141) & No-Hispano & Yacimiento sobre vía \\
\hline La Morterona (Saldaña, Palencia) & No-Hispano & $\begin{array}{l}\text { Yacimiento sobre vía (urbano/ } \\
\text { Necrópolis) }\end{array}$ \\
\hline Paredes de Navas (Palencia) & No-Hispano & Yacimiento sobre vía (urbano) \\
\hline Villa de Olmeda (Pedrosa de La Vega, Palencia) & No-Hispano & Villa/Necrópolis \\
\hline Iruña (Trespuentes, Villodas) & No-Hispano & Yacimiento sobre vía (urbano) \\
\hline Castro de yecla (Sto Domingo de Silos, burgos) & Pseudohispano & Castro \\
\hline San Miguel del Arroyo (Valladolid) & Pseudohispano & Necrópolis \\
\hline Liédena (Navarra) & Pseudohispano & Yacimiento sobre vía \\
\hline Santomé (San bernardo de Tibiás, Orense) & Pseudohispano & Castro \\
\hline Castillo Billido (Santa María de las Hoyas, Soria) & $\begin{array}{l}\text { Pseudohispano/ } \\
\text { No-Hispano }\end{array}$ & Castro \\
\hline Villa de Olmeda (Pedrosa de La Vega, Palencia) & $\begin{array}{l}\text { Pseudohispano/ } \\
\text { No-Hispano }\end{array}$ & Villa \\
\hline Iruña (Trespuentes, Villodas) & $\begin{array}{c}\text { Pseudohispano/ } \\
\text { No-Hispano }\end{array}$ & Yacimiento sobre vía (urbano) \\
\hline
\end{tabular}

En primer lugar decidimos analizar sólo los broches de claro significado militar (no-hispanos/pseudohispano) (tabla 4), puesto que una significación estadística negativa en su distribución invalidaría claramente nuestra proposición. La hipótesis no se cumpliría ni tan siquiera para aquellos elementos que manifiestan la existencia de militares. Sin embargo, se observa en el cuadro resultante como existe una clara significación estadística ( $p$ es menor que 0,05 ). Por lo tanto, el hecho de que haya más broches en localizaciones militares no obedece al azar y existe un nexo causal relacionado con nuestra proposición.

Seguidamente analizamos, también por separado, la distribución de los broches de tipo hispano (tabla 4) ya que la significación positiva de los broches de claro origen militar no era concluyente para los primeros, sobre todo si se tenía en cuenta que se había planteado un uso paramilitar rústico para su presencia (Aurrecoechea, 2007a: p. 444 y 2009: p. 493). Los resultados obtenidos reflejan una significación estadística aún mayor que en el caso de los broches militares ( $\mathrm{p}$ es mayor que 0,05 ). Debemos decir además que en este caso fuimos aún más rigurosos de lo que establecía el análisis ya que en la asignación de los casos a las localizaciones rústicas fueron incluidos aquellos casos ubicados en asentamientos indeterminados, que desde un procedimiento ortodoxo tendrían que haber sido eliminados del universo de estudio por poder asignarse a los dos grupos.

Finalmente, en el test en el que se analizan los dos tipos de broche (tabla 4) se observa cómo aumenta aún más la significación estadística y permite deducir la complementariedad en la distribución de estos elementos como expresión de una mayor eficiencia en las misiones asignadas a las guarniciones de tropas hispanas. 
Tabla 4. Resultados de los análisis estadísticos de elementos de cinturón en relación a su distribución espacial.

Broches no-hispanos/pseudohispanos (militares) (Tabla 4)

\begin{tabular}{|l|c|c|c|}
\hline & N observado & N esperado & Residual \\
\hline localización con función militar & 11 & 7,0 & 4,0 \\
localización rústica & 3 & 7,0 & $-4,0$ \\
Total & 14 & & \\
\hline
\end{tabular}

Broches hispanos

\begin{tabular}{|l|c|c|c|}
\hline & N observado & N esperado & Residual \\
\hline localización con función militar & 16 & 10,5 & 5,5 \\
localización rústica & 5 & 10,5 & $-5,5$ \\
Total & 21 & & \\
\hline
\end{tabular}

Ambos tipos de broche

\begin{tabular}{|l|c|c|c|}
\hline & N observado & N esperado & Residual \\
\hline localización con función militar & 27 & 17,5 & 9,5 \\
localización rústica & 8 & 17,5 & $-9,5$ \\
Total & 35 & & \\
\hline
\end{tabular}

Estadísticos de contraste

\begin{tabular}{|l|c|c|c|}
\hline & Broches militares & Broches hispanos & Ambos tipos de broche \\
\hline Chi-cuadrado(a,b,c) & 4,571 & 5,762 & 10,314 \\
gl & 1 & 1 & 1 \\
Sig. asintót. &, 033 &, 016 &, 001 \\
\hline
\end{tabular}

a 0 casillas $(, 0 \%)$ tienen frecuencias esperadas menores que 5 . La frecuencia de casilla esperada mínima es 7,0.

b 0 casillas $(, 0 \%)$ tienen frecuencias esperadas menores que 5 . La frecuencia de casilla esperada mínima es 10,5.

c 0 casillas $(, 0 \%)$ tienen frecuencias esperadas menores que 5 . La frecuencia de casilla esperada mínima es 17,5.

En conclusión, para los tres test realizados se descubre que existe una clara relación estadística respecto a la ubicación de los broches, tanto no-militares/pseudohispanos como hispanos, en localizaciones con función militar, por lo que dicha relación no responde al azar, es decir, existe un motivo que entendemos que se relaciona con las misiones encomendadas al ejército en la península ibérica en el sector norte-noroeste. Por otro lado, la distribución de estos broches refleja una importante dispersión de efectivos militares sobre la región analizada para cubrir los objetivos ordenados. Pero esta dispersión es mucho más amplia abarcando prácticamente la extensión total de la península ibérica. Desgraciadamente la falta de estudios sistemáticos sobre el itinerario preciso de las vías en otros sectores como el mediodía peninsular no permite confirmar las mismas conclusiones para la distribución de esta piezas en estas áreas; pero de los hallazgos de broches y atalajes de cinturón en asentamientos como Titulciam, Complutum o Sisapo parece deducirse que su presencia estaría relacionada con la existencia de guarniciones militares que estarían cumpliendo las funciones de policía del territorio, vigilancia viaria y control del tránsito de la annona a lo largo de la diócesis hispaniaurum. A esta misma conclusión llega el investigador García Moreno a partir del análisis de la situación 
de los cuarteles nombrados en la Notitia Dignitatum para la tropa hispana y su posible carácter ecuestre en la mayoría de las unidades (García, 2002: pp. 631-632 ).

\section{III.2. LA DISTRIBUCIÓN DEL EJÉRCITO COMO CAUSA DE SU DISOLUCIÓN}

En definitiva, la distribución de las piezas de cingula militiaea nos refleja una extensa dispersión de las guarniciones militares a lo largo de todo el territorio peninsular desde sus centros de acuartelamiento en el norte, por otra parte lógicas debido a las necesidades de llevar a cabo de manera efectiva las obligaciones encomendadas por la administración bajo imperial. A esta gran dispersión peninsular ha de sumarse la reducción en el número de soldados que se opera en las unidades del bajo imperio (de Francisco, 2011: p. 38; Duncan-Jones, 1990: pp. 105-117), que en el caso hispano ya era de por si reducido (Andrés, 2005: p. 414), y que se refleja en la ausencia de cecas en territorio peninsular en el bajo imperio (Arce, 1985: p. 155) y en la denominación de los oficiales al frente de los regimientos hispanos en la Notitita Dignitatum (García, 2002: p. 629). Todo ello debió repercutir en su operatividad bélica. Esta situación explicaría razonadamente los pasajes de las fuentes escritas relacionadas con la presencia o ausencia del ejército hispano en la confrontación producida en Hispania por la usurpación de Constantino III a principios del s. V. Efectivamente, la falta de respuesta ante la llegada del ejército del usurpador Constantino al mando de Gerontius se explica por la imposibilidad de crear una fuerza de interposición real rápida y efectiva del ejército hispano al estar la mayor parte de sus unidades desperdigadas en grupos de reducido tamaño por la totalidad del territorio. Así se explicaría el reclutamiento de las tropas regulares asentadas en las ciudades de Lusitania (Zosim., 6, 4, 3) para enfrentarse al ejército del usurpador por parte de Dídimo y Valeriano primos del legítimo emperador, Honorio. De la misma forma, la falta de operatividad bélica de unos soldados habituados tan sólo a funciones de carácter administrativo se refleja claramente en las fuentes cuando nos cuentan como estas tropas eran pocas e ineficaces por lo que los primos del emperador tuvieron que echar mano de sus propios recursos armando un ejército con sus propios siervos, colonos y esclavos (Zosim., 6, 4, 3; Sozom., 9, 11; Oros., 7.40).

Por otro lado, debemos tener en cuenta que, el envío de jueces y procuradores de Constantino III a Hispania en cuanto desembarca en la Galia y la ausencia en las fuentes de malestar ante esa ingerencia (Oros., VII, 40, 5-7) parece demostrar que el cambio de autoridades de la nueva administración se hizo de manera pacífica en casi todo el territorio, por lo que las funciones del ejército no debieron variar y las guarniciones siguieron actuando en los mismos lugares sin variación en sus actividades (Arce, 2005: p. 36).

Queremos remarcar que, según las fuentes, el descontento en la provincia llega cuando Constantino III sustituye con su ejército bárbaro de Honoriaci a los «rústicos locales» de la función, asignada desde antiguo, de proteger los pasos pirenaicos (Oros., VII, 40,8). Estos rústicos locales no pueden ser otro grupo que las guarniciones del ejército hispano que Orosio quiere describir tan gráficamente para diferenciarlo del ejército regular barbarizado, típico de su tiempo. El clérigo, de manera consciente, marcaría la diferencia entre la naturaleza de los dos ejércitos, uno extraño y bárbaro frente a otro de unidades autóctonas imbricado en el tejido social de la diócesis. Si tenemos en cuenta el carácter del ejército hispano-romano indígena, heredero biológica y culturalmente del auténtico ejército de tradición romana y orgullosos de su cometido en la defensa y vigilancia de su territorio no nos debe extrañar que haberlos apartado de su función tradicional por un grupo de «bárbaros advenedizos», por un falso ejército romano, lo hubieran considerado como una afrenta a su propio honor y al centro de su dignidad como institución militar. Este malestar o «rebelión» del componente hispano, en el 
que seguramente también influyó el saqueo de los campos palantini por los honoriaci al ser la seguridad del territorio otra de las funciones del ejército hispano, fue aprovechado por el General Geróntius para sublevarse contra Constantino III.

En definitiva, creemos que la falta de un mayor protagonismo del ejército hispano en las fuentes literarias tardo-antiguas se debe tanto a sus características singulares como a su carencia de choque ofensivo, como plantea el profesor Arce (2005: p. 42), más que a la inexistencia del mismo a finales del s. IV. Sin embargo, su presencia en Hispania no estaba concebida como una fuerza ofensiva si no que obedecía a un sistema geoestratégico de logística y estaba integrado en un sistema pasivo de defensa (de Francisco, 2011: p. 45; Luttwak, 1979: cap. III) donde su escaso número no lo hacía efectivo en campo abierto pero sí como guarniciones defendiendo la red de castellas y ciudades fortificadas de las provincias hispanas, como demuestra la distribución de los broches de cinturón. De esta manera, su efectividad sí quedó demostrada con la defensa estática efectuada contra la invasión de pueblos germanos a la Península Ibérica, pues así interpretamos el pasaje de Hydacio cuando nos dice que gran parte de los habitantes de Hispania se salvaron de las razzias de los germanos al refugiarse en las castra, Castella y ciudades del territorio (Hyd. XVII), lugares donde en muchos casos había guarniciones militares que contribuyeron con su experiencia a una buena defensa de los emplazamientos. Además, en la defensa efectiva también debió contribuir la falta de habilidad de los pueblos germanos en la poliorcética por lo que rehuían de asedios prolongados y asaltos a los recintos fortificados de entidad (Arce, 2005: pp. 215 a 217).

La desaparición del ejército hispano se producirá a lo largo del s. V de una manera lenta y progresiva a la misma vez que el poder central del imperio romano de occidente va debilitándose y perdiendo la capacidad para controlar efectivamente las provincias hispanas y para contrarrestar y defender a sus ciudadanos de la ingerencia de los pueblos germanos. El ejército regular y el gobierno central formaban parte de la misma realidad sociopolítica por lo que el debilitamiento y la desaparición del gobierno que había mantenido el ejército llevó parejo también el final de éste (de Francisco, 2011: p. 57). No obstante, parte de ese ejército hispano todavía seguía operativo en el año 420, pues de otra forma no entendemos el pasaje de Hydacio sobre el apoyo del ejército galo del general Astirius en campaña contra los vándalos de Gallaecia, de un número de tropas comandadas por el Vicarius hispaniarum Mariocellus que procedían del Sur peninsular, no de allende de sus fronteras (Hyd., XXVI).

El vacío de poder producido por el desmoronamiento del imperio romano de occidente en el s. V permitió que las grandes aristocracias locales de possesores, tanto civiles como religiosos, terminaran por hacerse dueños del control territorial y asumieran el mando de las ciudades donde se encontraban (Helal Ourriachen, 2008: p. 39). La intensificación del patrocinio de la aristocracia de potentes y possesores en unos territorios en los que el control de la administración imperial se iba extinguiendo hasta su total desaparición, afectó a las guarniciones militares hispanas que se aglutinaron en torno a dichos dominus en ejércitos privados (Pérez, 1998: p. 289) que, protegían sus grandes posesiones rústicas o las ciudades que gobernaban, en este último caso como elementos de autodefensa de dichas urbes (Sanz, 1986: p. 64).

\section{EL EJÉRCITO EN CÂSTULO}

Quizás pueda sorprender la existencia de unidades militares en una ciudad como Cástulo, tan meridional a los acuartelamientos principales del ejército bajo imperial.

Sin embargo, existen algunas referencias literarias y numerosas evidencias arqueológicas que identifican la existencia permanente de tropas romanas tanto en ella como en su territorio 
desde época republicana. Así pues, acabados los hechos bélicos de la segunda guerra púnica acontecidos en la península ibérica, donde el bando romano se alza victorioso y se anexiona Cástulo a partir de un foedus (Livio XXVIII, 19), observamos como entre los s. II y I a. C. el ejército romano va a utilizar Cástulo como lugar de invernada y centro de operaciones para conquistar o pacificar buena parte del Sur y centro peninsular (Livio XXXV, 22, 5) o dirimir conflictos civiles surgidos en Roma.

Pero es el registro arqueológico el que permite pensar en un establecimiento continuo y cotidiano de guarniciones militares en el territorio castulonense en estas fechas por el interés de Roma en la explotación minero-metalúrgica de los ricos filones metálicos de la zona. El interés por el beneficio del metal llevó al estado romano a una compleja articulación de control territorial, en donde una serie de recintos fortificados denominados «Castilletes» vigilarían las explotaciones mineras y las rutas interiores de una sierra como el Saltus Castulonense aislada, abrupta y alejada de los grandes centros urbanos y, por tanto, un lugar propicio de revueltas por los grupos mineros o para la existencia de salteadores (Arboledas, 2010: pp. 184 y 186), como lo demuestra la carta que Asinio Polión, legado de Julio Cesar en la Ulterior desde el año 44 a.C., escribió a su amigo Cicerón, en la cual hace referencia a los constantes latrocinios que se producían en esta zona (Contreras de la Paz, 1960: p. 150). Los encargados de llevar a cabo el trabajo de policía y la vigilancia y control de la producción y transporte de los metales desde esos asentamientos fortificados (Gutiérrez et alli, 2009: p. 361 y 362) no pueden ser otros que vexilliationes desplazadas a esas zonas desde sus centros de acuartelamiento permanente en el norte peninsular, como también se ha constatado en la comarca de La Serena en Extremadura, donde se observa un patrón de asentamiento similar y dónde se han hallado pruebas evidentes del control de la producción minera por parte del ejército (Ortiz y Rodríguez, 2004: p. 93 y 94).

La reforma provincial de Augusto, a comienzos del alto imperio, no hizo más que afianzar y justificar legalmente la existencia del ejército en la zona, puesto que la inclusión de Cástulo y su territorio en una provincia al mando directo del emperador permitía la presencia del mismo sin ninguna otra justificación. De esta manera, Augusto reserva para el fisco imperial una zona de gran riqueza que va a reformar para una explotación más eficiente y que se aprecia en el registro arqueológico con una reducción del número de explotaciones centradas en los yacimientos más importante. De esta forma, el número de recintos fortificados también se reducen. Por último, el final de estos recintos irá paralelo también a la reducción de la actividad minera entre finales del s. I y principios del s. II (Arboledas, 2010: p. 186).

Esta claro que, en la organización de esta actividad minera, Cástulo como ciudad estratégicamente situada en el área minera y como nudo de comunicación entre el sur, el levante y el centro peninsular posibilitó que se convirtiera el centro neurálgico y comercial de la región minera (Arboledas, 2010: p. 186). Cástulo debió ser el centro administrativo de la zona y el cuartel general de las unidades militares dispersas por la región, donde se encontraba la oficialidad y posiblemente los soldados asignados al oficcium del procurator metalorum que debió operar en la zona (Arboledas, 2010: p. 196). De hecho se constata un destacamento militar en la ciudad (Blázquez, 1991: p. 51) pues se conoce una basa epigráfica de mediados del s. I hallada en Cástulo donde la cohorte Servia Ivvenal rinde homenaje al Juez decurional Quinto Cornelio Valeriano y a su esposa, Titia Optata (CIL II 3272) (Contreras de la Paz, 1999: p. 94).

Sin embargo, el servicio de policía y el control de la minería no van a ser las únicas funciones asignadas a los destacamentos militares desplazados en la zona sino que también van a ejercer tareas de aprovisionamiento de productos agrícolas para su uso militar. Las inscripciones religiosas elevadas por efectivos militares en Vivatia (Baeza), Tugia (Toya) o Isturgi (Andújar) ubicadas en torno a Cástulo y siguiendo la importante vía Augusta demuestran la función de control y vigilancia de convoyes de productos estratégicos, tanto metálicos como alimentarios, 


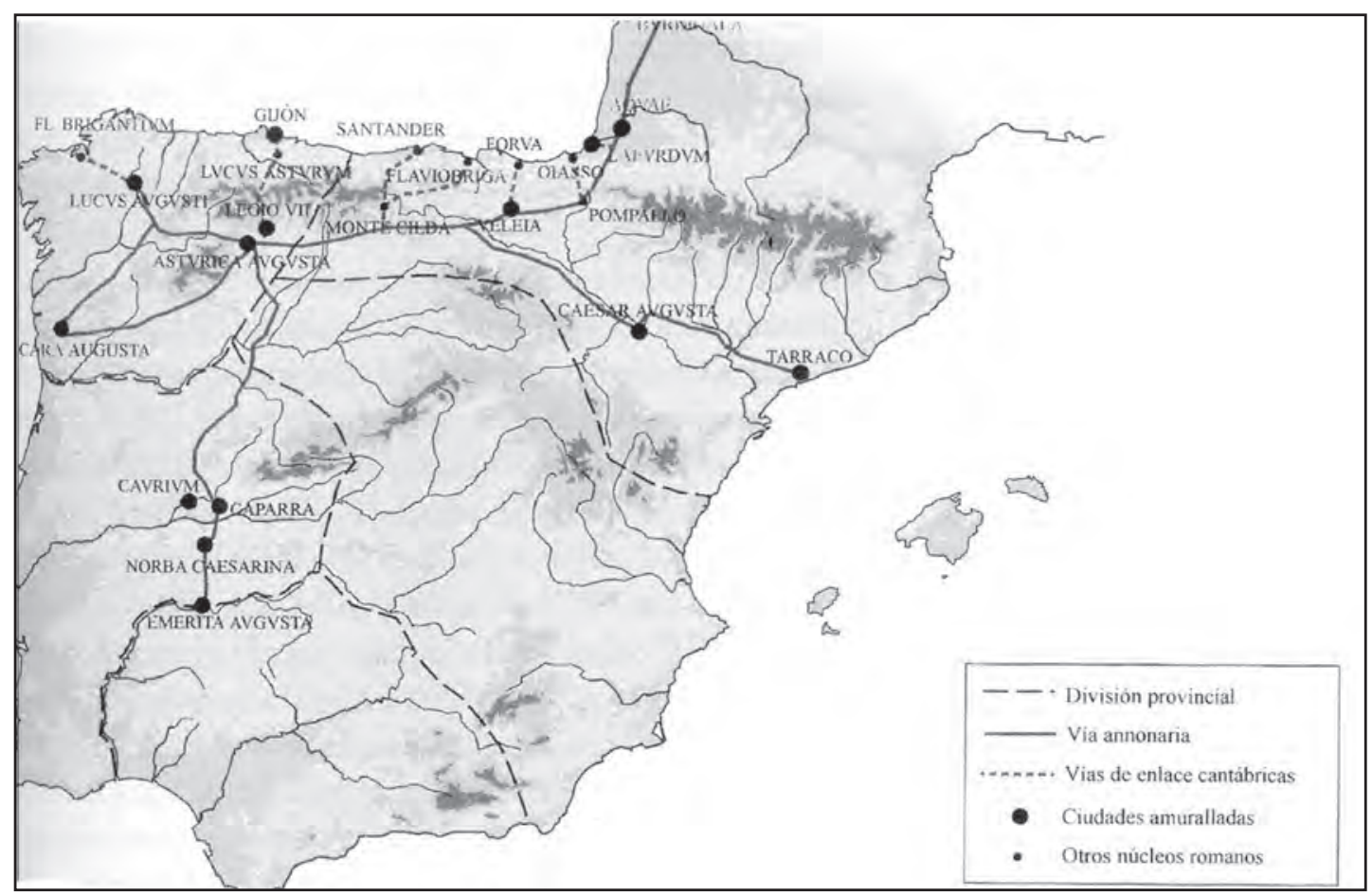

Figura 4. Recintos amurallados bajoimperiales y principales vías anonarias según Fernández y Morillo; 2003: 585; fig. 1).

de uso militar para la administración imperial (Andrés, 2005), pero la inscripción de Obulco (Porcuna) también permite pensar en una fiscalización directa de los productos agrícolas puesto que la riqueza de esta ciudad bética se basaba, fundamentalmente, en los recursos agropecuarios como queda demostrado tanto por su situación geográfica como por las emisiones monetarias del s. I a.d. C. donde se puede apreciar en su reverso un arado y una espiga de trigo.

Cástulo como nudo de comunicaciones estratégico tuvo que jugar un papel fundamental en la articulación de todas estas actividades, por lo que la presencia del ejército en la ciudad no varió cuando la actividad minera empezó a declinar, a principios del s. II ya que además esto se suplió con un desarrollo de la producción agropecuaria en la depresión de Linares-Bailén (Arboledas, 2007: p. 756), elemento fundamental en el avituallamiento de las tropas.

Por tanto, la presencia de ejército en Cástulo en el bajo imperio partía de una pauta anterior donde los destacamentos militares daban un servicio similar a los de otras zonas de la península ibérica en donde estaban asignados. Pero entendemos que la continuidad de la presencia de destacamentos significativos de ejército romano en el bajo imperio, como lo demuestra los broches de tipo Simancas hallados en la ciudad, estaría motivada por ser una ciudad estratégicamente situada como nudo principal de comunicaciones desde donde conectaba la red viaria de transporte desde el sur y sureste a las áreas centrales, septentrionales y orientales de la península. De esta manera, Cástulo siguió siendo un lugar importante para la política de la administración imperial relacionada con sus nuevas necesidades geoestratégicas, donde la península ibérica jugaba un papel destacado como suministradora de la annona militaris a los ejércitos del limes. Así, la reedificación de la muralla de Cástulo constatada a finales del s. III (Choclán y Campos, 2005 en. prensa) demostraría la inclusión de la ciudad en el sistema de red de estaciones intermedias de fiscalización y control de la annona hacia el norte. 
Si la administración imperial planificó una nueva articulación territorial desde el punto de vista militar, que tenía como objetivo primordial el aprovechamiento militar de los cereales meseteños y lusitanos (fig. 4), sería extraño pensar que la zona meridional de la península no hubiera estado dentro de ese plan productivo, teniendo en cuenta que era conocido desde antiguo la proverbial riqueza agraria de la Baetica (Strab. III, 6) y que desde el alto imperio había sido utilizada con ese fin (aceite bético). La parte occidental de la Baetica seguramente estaba controlada por la propia Emerita Augusta por lo que la misma capital hispana se convirtió en uno de los gestores de partida de los abastecimientos agrícolas del suroeste peninsular que llevaba la annona por la vía de la Plata hasta el norte y de allí a Aquitania. Pero la parte occidental quedaba demasiado alejada, Cástulo como ciudad ubicada en el Alto Guadalquivir, justo al noreste de la Baetica, y nudo de comunicaciones con el centro, norte y este peninsular debió ser la ciudad idónea para convertirla en uno de los centros de control fundamental de la annona fiscalizada en el sureste de la Baética (fig. 5). De esta manera, el mapa de las vías anonarias del bajo imperio y la planificación territorial militar con una situación, a nuestro entender, demasiado excéntrica se resuelve de manera más eficaz si se une con las vías que comunican Cástulo con el norte. Algo que ya planteaban de alguna manera Morillo y otros cuando, ante los casos de los amurallamientos de enclaves como Tiermes o Caesaraugusta, plantean la posibilidad de extender esa planificación a otros lugares diferentes al Norte y Noroeste peninsular, aunque siempre para regiones más septentrionales que la que nosotros presentamos (Fernández y Morillo, 1997: pp. 739 y ss.).

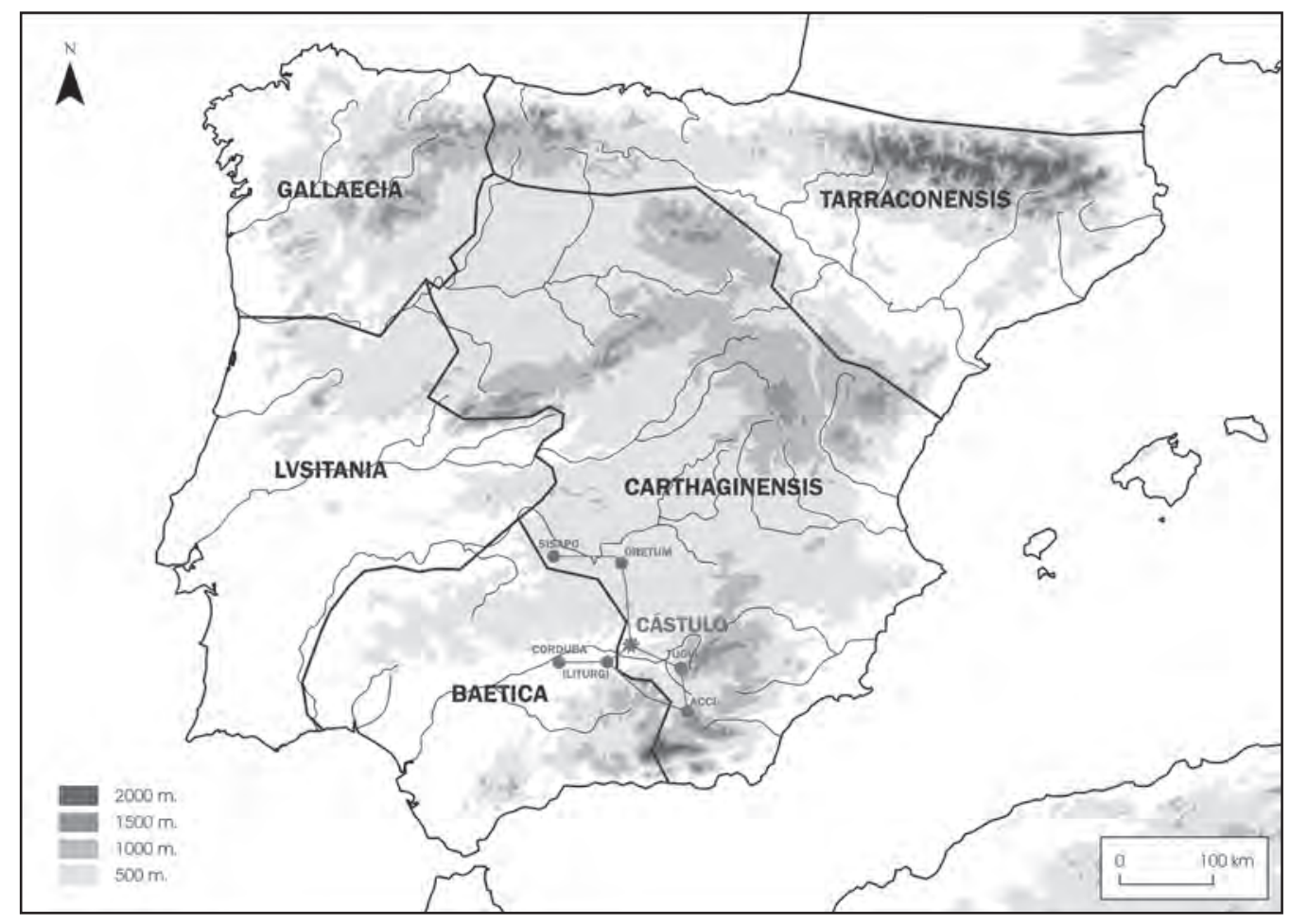

Figura 5. Situación de Cástulo y su relación con la red viaria romana.

Por tanto, el ejército que se encontraba en Cástulo siguió permaneciendo en la ciudad, si bien quizás con algunos efectivos más para llevar a cabo de manera más eficiente el control 
de los avituallamientos. En este sentido, el hallazgo de una gran superficie pavimentada al exterior de la Puerta Norte de Cástulo fechada en la segunda mitad del s. IV y que se ha interpretado como un mercado (Choclán et alli, 2010: p. 1848) podría estar también relacionada con el control, almacenaje puntual y transporte de la anona.

De esta forma, los broches de cinturón de tipo Simancas hallados en Cástulo pertenecerían a soldados del ejército hispano desplazados a la ciudad fundamentalmente para controlar la annona, pero también estarían encargados del servicio de policía, como demuestra la existencia de una hebilla de broche en el Castro del Collado de Los Jardines en pleno Saltus castulonenses. Es decir, las funciones específicas que le fueron encomendadas al ejército hispano en el s. IV.

\section{AGRADECIMIENTOS}

En primer lugar queremos dar la gracias a $\mathrm{D}^{\mathrm{a}}$ Isabel Estévez, por su apoyo moral que nos ha dado fuerzas para poder concluir este trabajo y, como no, por haber realizado la traducción del resumen. Al Director del Museo Arqueológico de Cástulo, D. Marcelo Castro por su incondicional ayuda y sus juiciosos consejos en la elaboración de este trabajo. A nuestro amigo y colega D. Narciso Zafra por sus orientaciones en la elaboración de los gráficos. A los especialistas en vías Romanas D. Isaac Moreno y D. Jesús Rodríguez por su inestimable y generosa ayuda respecto a la relación entre algunos yacimientos y su ubicación sobre las calzadas romanas. Por último, nuestro más profundo agradecimiento a nuestros Colegas $\mathrm{D}^{\mathrm{a}}$ Concepción Choclán y D. Daniel Campos por dejarnos acceder, antes de ser publicados, a sus trabajos sobre la excavación del sector Noreste de la Muralla de Cástulo. A todos ellos muchas gracias.

\section{BIBLIOGRAFÍA}

Alonso-Núñez, J.M. (1990): “Aspectos de la Hispania romana del S. IV. Límites cronológicos y consideraciones sobre las fuentes para su reconstrucción histórica”. Studia Histórica, Historia Antigua, 8:7-10. Salamanca.

Andrés, G. (2005): Una aproximación a la religión del ejército romano imperial: Hispania. Edit. Universidad de La Rioja, Logroño.

Arboledas, L. (2010): "La explotación masiva de los recursos mineros de Sierra Morena Oriental: La minería iberorromana”. La minería y la metalurgia en el Alto Guadalquivir: desde sus orígenes hasta nuestros días. Edit. I.E.G.: 123-202. Jaén.

Arce, J. (1985): "La administración económica de la "Diócesis Hispaniarum” en el siglo IV d.C. Rev. Pyrenae, 21: 151-156.

Arce, J. (1997): El último siglo de la España Romana (284-409). Edit. Alianza Editorial, Madrid.

Arce, J. (2005): Bárbaros y romanos en Hispania (400-507 A.D). Edit. Marcial Pons, Madrid.

Aurrecoechea, J. (1995/1996): "Las guarniciones de cinturón de atalaje de tipología militar en la Hispania Romana, a tenor de los bronces hallados en la Meseta Sur. En Estudios de prehistoria y arqueología Madrileña, 10, pp. 49-99.

Aurrecoechea, J. (2001): Los cinturones romanos en la Hispania del Bajo Imperio. Monographies instrumentum, 19. Edit. Monique Mergoil, Montagnac.

Aurrecoechea, J. (2007a): “El equipo militar en la Hispania del bajo imperio”. Rev. Sautuola, 13:427444. Santander.

Aurrecoechea, J. (2007b): "Las armaduras segmentadas (loricae segmentatae) en los yacimientos romanos de la provincia de León: un estudio de conjunto”. Archivo Español de Arqueología, 80:153-182.

Aurrecoechea, J.(2009): "El equipo militar tardorromano en Hispania: identificación y análisis espacial”. Gladius, Anejos, 13: 481-496. Madrid 
Aurrecoechea, J.; Fernández, C. y Caballero, A. (1986): "Mobiliario metálico del yacimiento ibero-romano de La Bienvenida en la provincia de Ciudad Real”. Rev. Oretum, II: 251-292. Ciudad Real

Bhöme, H.W. (1974): Germanische Grabfunde des 4. bis 5. Jahrhunderts zwischen unteren Elbe und Loire. München.

Blázquez, J.M. (1991): Agricultura y minería romanas durante el Alto Imperio. Historia del mundo antiguo, Vol. 54. Edit. Akal, Madrid.

Blázquez, J.M. y García-Gelavert, M.P. (1999): Cástulo, Jaén, España. II. El Conjunto Arquitectónico del Olivar. Edit. BAR International Series, 789, Oxford.

Cañizar, J.L. (1998): "Posibles causas de deserción en el ejército romano vistas a través del Codex Theodosianus. Problemática bajo Constantino y problemática a partir de la segunda mitad del siglo IV D.C.” Studia Histórica, Historia Antigua, 16:217-232. Salamanca.

Carreras, C. (1997): "Los beneficiarii y la red de aprovisionamiento militar de Britannia e Hispania”. Rev. Gerión, 9: 151-176.

Carretero, S. (1999): "El ejército romano del Noroeste Peninsular durante el Alto Imperio. Estado de la cuestión”. Gladius, 19: 143-156. Madrid.

Castillo, E. (2004): Avgvsto: fundador de Emerita. Edit. Fundación El Monte y Fundación de Estudios Romanos, Mérida.

Chias, P. y Abad, T. (2008): “La construcción del territorio: caminos y puentes en Castilla y León". Historia de las Obras Públicas en Castilla y León: Ingeniería, Territorio yPatrimonio, Edit. Colegio de Ingenieros de caminos, canales y puertos: 299-414.

Choclán, C.; Barba, V; Navarro, M. y Fernández, A. (2010): “Intervención arqueológica en la necrópolis iberorromana de la Puerta Norte de Cástulo, linares (Jaén)”. Anuario Arqueológico de Andalucía, 2005; edit. Junta de Andalucía (C.D.):1838-1850.

Contreras, R. (1960): "Bandolerismo hispano y guerra civil en el Salto Castulonense en el año 43 anterior a la Era Cristiana (de una carta de Asinio Polión a Cicerón)”, en Revista Oretania, nº . 4; pp.149-154. edit. Museo Arqueológico de Linares.

Contreras, R. (1999): Historia biográfica de la antigua Cástulo. Edit. Cajasur, Córdoba.

Choclán, C. y Campos, D. (2005):”Intervención en el lienzo noreste de la Muralla de Cástulo (Linares)”. Anuario Arqueológico de Andalucía. Sevilla. En prensa.

Domínguez, A.J. (1983): "Los ejércitos regulares tardorromanos en la Península Ibérica y el problema del pretendido limes hispanus." Revista Guimarâes, 93: 101-128.

Duncan-Jones, R. (1990): Structure and Scale in the Roman Economy. Edit. Cambridge University Press, Cambridge.

Escribano, M.V. (2000): “Usurpación y defensa de las Hispanias: Dídimo y Veriniano (408)”. Gerión, 18: 509-534.

Fernández, C. y Morillo, A. (1994): De Brigatium a Oiasso. Una aproximación al estudio de los enclaves marítimos cantábricos en época romana. Madrid.

Fernández, C. y Morillo, A. (1997): "La muralla de Iruña en el contexto de las fortificaciones urbanas bajoimperiales de la región septentrional de la Península Ibérica”. Isturiz, 9: 735-742.

Fernández, C. y Morillo, A. (2002): "Entre el prestigio y la defensa: la problemática estratégico-defensiva de las murallas tardorromanas en Hispania”. Gladius, Anejos, 5: 577-589. Madrid.

Feugère, M. (2002): "Militaria de Gaule Méridionale, 19. Le Mobilier militaire Romain dans le département de L'Herault (F)”. Gladius, 22: 73-126.

Francisco de, A. (2011): “El ejército Romano del Bajo Imperio”. Ab Initio, 2: 29-60.

Fuentes, A. (1986): "Tres nuevos botones tardorromanos en el Museo de Ciudad Real". Rev. Oretum, II: 322-331. Ciudad Real.

García, L.A. (2002): “Asentamientos militares tardorromanos en las Españas”. Gladius, Anejos, 5: 625636. Madrid.

Goffman, E.: Internados. Ensayos sobre la situación social de los enfermos mentales, Amorrortu, Buenos Aires, 1970.

Guàrdia, J.; Maragall, M.; Mercadal, O.; Olesti, O.;Galbany, J. y Nadal, J. (2007): "Enterrament d'época tardoromana d'un macaco amb "aiovar” al jaciment de Les Colomines (Llívia, La Cerdanya)”. Rev. Empuries, 55: 199-227.

Gutiérrez, L.M.; Bellón, J.P. y Rueda, C. (2009): "The military control of the mining territory of eastern Sierra Morena”. Gladius, Anejos, 13: 351-364. Madrid. 
Helal Ouriachen E. H. (2008): La ciudad Bética Durante la Antigüedad Tardía: Persistencia y mutilaciones locales el relación con la realidad urbana de las regiones del Mediterráneo y del Atlántico; en Universidad de Granada. Dpto. de prehistoria y Arqueología . Tesis digital

Iriarte, A.; Filloy, I. y Gil, E. (2000): "Late Roman military equipment from the city of Iruña/Veleia (Álava, Spain)”. Journal of roman military equipment studies, 11: 25-36.

Luttwak, E. (1979): Grand Strategy of the Roman Empire. John Hopkins University Press, Baltimore.

Martín, E.M. y San Gregorio, D. (2008): "La necrópolis tardorromana del Soto de Tovilla (Tudela de Duero, Valladolid)". Rev. digital Estudios del Patrimonio Cultural, 1:19-32.

Moreno, I. (2001): Descripción de la vía romana de Italia a Hispania en las provincias de Burgos y Palencia. Edit. Excma. Diputación de Burgos y Palencia. Salamanca.

Moreno, I. (2002): "Infraestructura viaria romana II”. I Congreso de las obras Públicas Romanas. Mérida.

Moreno, I. (2004): "III. El camino aragonés". Rev. Cimbra, 359: 1-18.

Moreno, I. (2006): "Vías romanas de Astorga". III Congreso de las Obras Públicas Romanas: 23-65.

Moreno, I. (2010a): "Vías romanas: Las huellas de la ingeniería perdida". V. Congreso de las Obras Públicas Romanas, en http:// www.traianvs.net: 11-46.

Moreno, I. (2010b): "Vías romanas: e infraestructuras modernas”. I. Congreso Internacional de Carreteras, Cultura y Territorio, en http:// www.traianvs.net: 1-22.

Morillo, A. (2003): “Los campamentos romanos de Astorga y León”. Espacio, Tiempo y Forma, Serie II, Historia Antigua, 16: 83-110.

Morillo, A. (2006): “Abastecimiento y producción local en los campamentos romanos de la región septentrional de la Península Ibérica”. Arqueología militar romana en Hispania II: producción y abastecimiento en el ámbito militar; coord. por Ângel Morillo Cerdán. Edit. Universidad de León. León.

Morillo, A. y García, V. (2009): "The Roman Camps at León (Spain): state of the research and new aproaches”. Gladius, Anejos, 13: 389-406. Madrid.

Morillo, A. y Martín, E. (2005): "El ejército romano en la Península Ibérica. De la "arqueología filológica” a la arqueología militar romana.” Rev. Estudios Humanísticos. Historia, 4: 177-207.

Núñez, J. y Sáenz, F. (2005): "Una mutatio de la vía ab Astúrica Burdigalam en Mariturri (Vitoria/ Álava)”. Archivo Español de Arqueología, 78: 189-207.

Ortiz, P. y Rodríguez, A. (2004): "La torre de Hijoviejo: Génesis, evolución y contexto de un asentamiento fortificado en la Serena (Badajoz)". Torres, atalayas y casas fortificadas: Explotación y control del territorio en Hispania (S. III a. de .-S. I d.de C., Edit. P. Moret y T. Chapa, Universidad e Jaén, Jaén: 77-95.

Palomino, A.L., Arbizu, M. y Negredo, M.J. (2006): "Documentación y diagnóstico del trazado de la Vía Romana de Italia a Hispania a su paso por las provincias de Burgos, Palencia y León”. III. Congreso de las Obras Públicas Romanas. Astorga: 87-112.

Paz, J.A. (2002): "Noticia sobre un hallazgo numismático y de piezas metálicas de la antigüedad tardía en Maderuela (Vera de Moncayo, Zaragoza).” Turiaso, XVI: 45-63.

Pérez, D. (1998): "Defensa y territorio en la sociedad peninsular hispana durante la antigüedad tardía (SS. V-VII)”. Studia Histórica, Historia Antigua, 16: 281-300. Salamanca.

Pérez, F. (1992): "Los cingula militiae tardorromanos de la Península Ibérica”. Boletín del Seminario de Estudios de Arte y Arqueología, 58: 239-261.

Pérez, F. (2002): "Un nuevo cinturón militar tardorromano Tipo Trier-Muri, procedente de la necrópolis de Hornillos del Camino (Burgos)” Gladius, Anejos, 5: 577-589. Madrid.

Pérez, F. y Viñe, A. (1989-1990): "Los cingula militiae tardorromanos y el inicio de la presencia de tropas de origen germánico en Hispania en los siglos IV y V.” Rev. de Historia, 10: 95-108. Cáceres.

Sanz, R. (1986): “Aproximación al estudio de los ejércitos privados en Hispania durante la antigüedad tardía”. Rev. Gerión, 4: 225-264.

Solana, J.M. (1994-1995): "La red viaria de la submeseta septentrional de Hispania según los itinerarios y testimonios miliarios”. Memorias de historia antigua, 15-16: 275-290

Solana, J.M. y Sagredo, L. (1998): La política viaria en Hispania. Siglo IV D.C. Edit. Universidad de Valladolid, Salamanca.

Solana, J.M. y Sagredo, L. (2006): La red viaria Romana en Hispania: Siglo I-IV D.C. Edit. Universidad de Valladolid, Salamanca. 
Sommer, M. (1974): Die Gürtel und Gürtelbeschläge des 4. und 5. Jahrhunderts im römischen Reich. Bonner Hefte zur Vorgeschichte, 22. Bonn.

Vallejo, M. (1993): “Sobre la persecución y el castigo a los desertores en el ejército de Roma”. Polis, 5: 241-251.

Villaverde, N. (2001): Tingitana en la antigüedad tardía (Siglos III-VII). Edit Real Academia de la Historia. Madrid.

Recibido: 09/05/11

Aceptado: 21/06/13 